\title{
Denying Antecedents and Affirming Consequents: The State of the Art
}

\section{DAVID GODDEN}

Department of Philosophy

Old Dominion University

Norfolk, Virginia 23529

U.S.A.

dgodden@odu.edu

\section{FrANK ZENKER}

Department of Philosophy and Cognitive Science

Lund University

Box 192, 22100 Lund

Sweden

frank.zenker@fil.lu.se

\begin{abstract}
Recent work on conditional reasoning argues that denying the antecedent [DA] and affirming the consequent [AC] are defeasible but cogent patterns of argument, either because they are effective, rational, albeit heuristic applications of Bayesian probability, or because they are licensed by the principle of total evidence. Against this, we show that on any prevailing interpretation of indicative conditionals the premises of DA and AC arguments do not license their conclusions without additional assumptions. The cogency of DA and AC inferences rather depends on contingent factors extrinsic to, and independent of, what is asserted by DA and AC arguments.
\end{abstract}

Résumé: Des publications récentes sur les raisonnements conditionnels qui emploient la négation de l'antécédent [NA] et l'affirmation du conséquent $[\mathrm{AC}]$ soutiennent que ce sont des formes de raisonnement logiquement critiquables mais probantes, soit parce qu'elles sont des applications efficaces, rationnelles, quoique heuristiques, de la probabilité bayésienne, ou soit parce qu'elles sont autorisées par le principe de preuve totale. Face à cela, nous montrons que selon une interprétation prédominante des phrases conditionnelles indicatives, les deux prémisses des arguments NA et AC n'appuient pas leurs conclusions sans des prémisses supplémentaires. Le bien-fondé ces arguments dépend plutôt de facteurs contingents extrinsèques et indépendants de ce qui est avancé par des arguments DA et AC

Keywords: affirming the consequent, Bayesian probability, conditional perfection, denying the antecedent, fallacy, heuristics, total evidence

(C) David Godden and Frank Zenker. Informal Logic, Vol. 35, No. 1 (2015), pp. 88-134. 


\section{Introduction}

This paper addresses two well-known forms of traditionally fallacious inference: denying the antecedent [DA] and affirming the consequent [AC] (Hamblin, 1970, pp. 25-27; Kneale and Kneale, 1962, p. 130; Sanford, 2003, pp. 19-20). In natural language argumentation we nevertheless frequently offer and accept arguments instantiating DA and AC structures (Evans and Over, 2004, chs. 3,4). When is it reasonable to do so?

Most extant treatments seek to specify conditions under which DA or AC can be cogent. ${ }^{1}$ Among these, the interpretive strategy transforms deductively invalid DA and AC surface structures to reveal deductively valid deep structures (Burke, 1994: Moldovan, 2009). The dialectical strategy, by contrast, restricts the function of DA to a refutation by premise denial such that DA shows a conclusion to be unacceptable because the supporting reasons in the initial argument are rejected (Godden and Walton, 2004). Similarly, Woods (2013) specifies defeasible retraction contexts in which DA-like moves are acceptable.

More recent work argues that DA and AC are ordinarily cogent because their surface structure can be inductively probative, and that DA and AC structures may be prudentially employed when viewed as an application of Bayesian probability. Specifically, Stone (2012) argues that DA arguments are probative and even cogent on the grounds of the principle of total evidence: if an antecedent is positively relevant to its consequent, then its negation should be negatively relevant - and sometimes sufficiently so. Similarly, Floridi (2009) argues that DA and AC can be viewed as applications of Bayes' theorem that take "informational shortcuts" such as assuming that there are no false

\footnotetext{
${ }^{1}$ We use 'cogent' to mean well-reasoned: a generic, theoretically-neutral, objective, normative standard of argumentative or inferential goodness. A cogent argument is one that meets some situationally appropriate standard of reason-giving. This standard can be variously explained and operationalized (e.g., epistemically, dialectically, etc.) and may properly be informed by factors that are not purely logical or epistemic, for instance by the practical or moral significance of an issue. Generally, cogency is analyzed as premise acceptability, relevance, and inferential sufficiency, where these criteria are understood to include dialectical adequacy such as successfully surviving pertinent criticism or objection. We use 'incogent' to mean not-cogent. Further, we use the term 'probative' to describe an argument or inference that provides a reason for its conclusion - that is, its premises provide some quantity of support for its conclusion, even if that support is not sufficient to establish the conclusion according to some appropriate standard of evidence.
}

(C) David Godden and Frank Zenker. Informal Logic, Vol. 35, No. 1 (2015), pp. 88-134. 
positives in the domain of application. These authors conclude that ordinarily DA and AC are not erroneous patterns of reasoning.

Against this, we argue that, on any prevailing interpretation of ordinary indicative conditionals, arguments that deny the antecedent or affirm the consequent fail to be cogent whenever they conspicuously fail to cite as reasons the conditions on which the acceptability of their conclusions properly depends. As we show, the acceptability of the conclusion of DA and AC arguments depends on factors not asserted by the stated conditional, for instance the extent to which antecedent and consequent conditions coincide and covary (and likewise with the complement conditions). Having made this positive case against $\mathrm{DA}$ and $\mathrm{AC}$, we move on to show that these recent treatments fail to meet their burden of proof, which consists in showing that $\mathrm{DA}$ and $\mathrm{AC}$ arguments as stated are generally cogent. We conclude by revisiting the question of whether $\mathrm{DA}$ and $\mathrm{AC}$ remain best treated as fallacious.

Section 2 is a brief overview of the issues informing the prevailing interpretations of indicative conditionals. Section 3 reviews extant logical, pragmatic, and dialectical approaches to DA and AC. Section 4 illustrates that, on any prevailing interpretation of indicative conditionals, the cogency of DA and $\mathrm{AC}$ depends on factors not asserted in the stated inference. Section 5 turns to probabilistic treatments and provides a critical response to arguments raised by Stone (2012). Section 6 briefly treats the interface between classical logical and probabilistic inference. Section 7 offers our conclusions.

\section{Interpreting indicative conditionals}

Minimally, an indicative conditional of the form $a \rightarrow c$ ordinarily asserts that the truth of its antecedent, $a$, is incompatible with the falsity of its consequent, $c$, under some appropriate modality. ${ }^{2}$ Examples include statements of default rules, statistical reg-

\footnotetext{
${ }^{2}$ Using the arrow ' $\rightarrow$ ' to represent indicative conditionals and the horseshoe ' $\supset$ ' to represent truth-functional, material conditionals, we attempt here to capture the central connotation of indicative conditionals as ordinarily used. This is complicated in unusual cases where antecedents are logically false, or where consequents are logically true, or where the antecedent and consequent have the same non-logical content (e.g., $a \rightarrow \sim a$ ). We use the term 'ordinary' to indicate this limited usage of conditionals and exclude the anomalous con-
} 
ularities or covariations, as well as presumptive indicators and conditions. This suggests a truth-functional interpretation of ordinary indicative conditionals (e.g., Bennett's (2003) "did-did" conditionals) on which they are interpreted as material (or Philonian). That is, $a \rightarrow c$ can be taken to imply $a \supset c$, which is equivalent to $\sim(a \& \sim c), \sim a \vee c$, and $\sim a \vee(a \& c)$. On this account, a conditional is truth-functionally defined as true whenever either its antecedent is false or its consequent is true. Ordinarily, the conditionals assert a factually sufficient/necessary relationship between their components:

\section{Relationship of a material conditional's components If sufficient condition then necessary condition.}

Although there is a prima facie case for mutual entailment between indicative and material conditionals, interpretative issues arise when reading ordinary indicative conditionals as material. ${ }^{3}$ We now consider two particular problems that motivate alternative readings of indicative conditionals in ordinary speech and argument.

structions just mentioned, which are aberrant in the course of ordinary conversation and reasoning.

Ordinary uses of material conditionals assert the incompatibility of a true antecedent and a false consequent as a matter of fact. Conditionals with a stronger modality include necessarily true ones (where the antecedent entails the consequent) and counter-factually true ones (that state nomological generalizations or laws of nature). Though only contingently true, material conditionals are also strictly true-i.e., exceptionless - while conditionals with a weaker modality, often called normic (Scriven, 1959), are exceptionadmitting, and hence not strictly but normally or generally true, or true by default. Such conditionals assert the incompatibility of a true antecedent and a false consequent normally, or ceteris paribus.

${ }^{3}$ Supposing indicative conditionals to be truth-functional, the tough entailment is from the material to the indicative. Jackson's (1987, p. 5) passage principle purportedly shows that we ordinarily pass between linguistic formulations involving compounds of negation, disjunction, and conjunction that are logically equivalent to the material conditional and those involving ordinary conditionals. Jackson's examples are: (i) "Suppose I am told that either the butler did it or the footman did it, then I may infer that if the butler did not do it, the footman did," thus illustrating that we generally take $a \vee c$ to entail $\sim a \rightarrow c$; (ii) "Suppose I am told that the butler and the footman are not both innocent, then I may infer that if the butler is innocent, the footman is not," thus illustrating that we generally take $\sim(a \& c)$ to entail $a \rightarrow \sim c$. Edgington $(1995 ; 2009)$ summarizes various reasons that support or refute a truthfunctional interpretation of indicative conditionals.

(C) David Godden and Frank Zenker. Informal Logic, Vol. 35, No. 1 (2015), pp. 88-134. 
First, material conditionals are monotonic: their consequents are not subject to defeat when their antecedents are strengthened through additional conditions.

\section{Monotonicity of material conditionals$$
\text { If } a \supset c \text {, then }(a \& b) \supset c
$$

Hence, if $a$ is a genuinely sufficient condition for $c$, then the occurrence (or non-occurrence) of another condition $b$ does not affect $c .{ }^{4}$ But the conditionals that we ordinarily rely upon are normally subject to a variety of qualifiers (unless-clauses) that mark the absence of defeaters. For instance: "If the match is struck, it will light, unless it's wet or there's no oxygen in the room"; "If I promise to be there, I will be, unless I get hit by a bus." For the most part, unstated unless-clauses are presumed to apply (or not) as part of our shared background knowledge. In other cases, such conditionals are genuinely defeasible-while they hold generally, they are subject to exception. For instance, birds fly. Hence the conditional "if it's a bird then it flies" is normally true, although penguins, ostriches, and kiwis are examples of flightless birds. Such defeasible conditionals state generally sufficient rather than genuinely sufficient conditions.

The conditionals we rely upon in such cases, then, are nonmonotonic. They hold ceteris paribus, and so their consequents are subject to defeat by some potential defeater, $d$.

\section{Non-monotonicity of ordinary conditionals}

It is not the case that, if $a \rightarrow c$ then $(a \& d) \rightarrow c$; rather, sometimes $(a \& d) \& \sim c$.

\footnotetext{
${ }^{4}$ This reason seems to work for what we have called the ordinary usage of conditionals. Properly speaking, however, the monotonicity of $\supset$ is a consequence of its truth-functional definition, which makes $a \supset c$ equivalent to $\sim a \vee c$. Hence, in cases where $c$ is true, the truth-value of $a$ doesn't matter; therefore, conjoining further conditions to the antecedent makes no difference. In cases where $a$ is false, in contrast, conjoining additional antecedent conditions to $a$ will still produce a false antecedent. The logical moral here is that the monotonicity of $\supset$ does not concern the truth of a consequent when an antecedent is strengthened with additional conditions. Indeed, if $a \supset c$ is true because $a$ is false, $\sim c$ can be added to its antecedent, which may seem to prove that $a \supset c$ is not monotonic. But the monotonicity of $\supset$ really pertains to the conditional relation between $a$ and $c$ when $a \supset c$ is true; and this relation remains unaffected if an antecedent is conjunctively supplemented with additional conditions. We thank John Woods for bringing this to our attention.
}

(C) David Godden and Frank Zenker. Informal Logic, Vol. 35, No. 1 (2015), pp. 88-134. 
Some scholars have therefore proposed defeasible modus ponens [DMP] as a form of defeasible but presumptive inference (e.g., Walton, 2002; 2004, ch.4). DMP operates as a kind of default inference on the presumption that excepting or defeating conditions do not obtain. ${ }^{5}$ On Walton's account, DMP does not conduct truth from premises to conclusions; rather, it may be understood plausibilistically, if not probabilistically, as establishing a presumption in favor of its conclusion such that the burden of proof is shifted from the proponent to the opponent.

Second, a compelling intuition has it that the components of indicative conditionals must be suitably or relevantly connected, which renders an exclusively truth-functional analysis inadequate (Bennett, 2003, ch.2). Such intuitions are standardly evoked with the paradoxes of implication (where '|-' means 'is a valid consequence of').

$$
\begin{aligned}
& \text { Paradoxes of implication } \\
& \quad \sim a \mid-a \supset c \\
& \quad c \mid-a \supset c \\
& \mid-(a \supset c) \vee(c \supset a)
\end{aligned}
$$

According to the first paradox, for instance, conditionals with contingent antecedents we are inclined to deny end up being true regardless of the credence we place in their consequents given their antecedents. Counter-intuitively, then, to use an example from Edgington (2009), it would be irrational to deny both "The Republicans will win" $(a)$ and "If the Republicans win, income tax will double" $(a \supset c)$. Supplementing truth-functional accounts with Gricean pragmatic considerations can neutralize the paradoxes at the level of assertion, but they remain problematic at a doxastic level (Edgington, 2009).

Combined with Frank Ramsey's insight on what we do when reasoning conditionally, these paradoxes have come to inform subsequent theories of how conditionals work.

\footnotetext{
${ }^{5}$ Gordon, Prakken and Walton (2007) distinguish two kinds of defeating conditions that can be viewed as critical questions for presumptive argument schemes. An exception is a defeating condition which is presumed not to obtain. Opponents who raise an excepting condition as a rebuttal bear the burden of proof for it, as opposed to merely pointing out its possibility. An assumption, by contrast, marks a defeating condition that is presumed to obtain once its possibility is raised. It functions like a normal premise such that, when challenged, proponents bear a burden of proof that the assumption holds (i.e., that the defeating condition does not obtain).
}

(C) David Godden and Frank Zenker. Informal Logic, Vol. 35, No. 1 (2015), pp. 88-134. 
If two people are arguing 'If $p$, will $q$ ?' and are both in doubt as to $p$, they are adding $p$ hypothetically to their stock of knowledge, and arguing on that basis about $q ; \ldots$ they are fixing their degrees of belief in $q$ given $p$. (Ramsey, 1990 [1929], p. 247)

Ramsey does not understand the schema 'if $p$ then $q$ ' as a declarative sentence, but rather as a mechanism for belief updating - a pattern of reasoning. Conditional reasoning, Ramsey notes, appears to take the antecedent for granted and then attempts to see what follows. This suggests two alternative interpretations of ordinary indicative conditionals.

On a suppositional interpretation, the conditional still excludes the possibility of a true antecedent together with a false consequent. But its truth table is "gappy"-having no truthvalue when its antecedent is false. As Adams (1965, p. 175) put it, "a bet that 'if $p$ then $q$ ' is conditional-in force only if $p$ proves true, and in that case winning if $q$ is true, and losing if $q$ is false." Or, as Quine (1982) said:

An affirmation of the form 'if $p$ then $q$ ' is commonly felt less as an affirmation of a conditional than as a conditional affirmation of the consequent. If, after we have made such an affirmation, the antecedent turns out to be true, then we consider ourselves committed to the consequent, and are ready to acknowledge error if it proves false. If on the other hand the antecedent turns out to have been false, our conditional affirmation is as if it had never been made. (Quine, 1982, p. 21)

Quine's claim, we take it, is that sometimes utterances of 'if $p$ then $q$ ' do not assert conditional sentences, but are rather conditional assertions of their consequents: ' $q$, assuming that $p$ '.

A second interpretation that builds on Ramsey's insight is due to Stalnaker (1968), and is characterized by the following two tenets. First is a thesis about how deliberation on the truth or acceptance of conditional statements should occur.

First, add the antecedent (hypothetically) to your stock of beliefs; second, make whatever adjustments are required to maintain consistency (without modifying the hypothetical belief in the antecedent); finally, consider whether or not the consequent is then true. (Stalnaker, 1968, p. 102)

This view, which also considers belief-revision conditions rather than the truth conditions of sentences, agrees with the supposi-

(C) David Godden and Frank Zenker. Informal Logic, Vol. 35, No. 1 (2015), pp. 88-134. 
tional view that indicative conditionals assert "a conditional affirmation of the consequent." Specifically, Stalnaker (p. 101) claimed, "[y]our belief about the conditional should be the same as your hypothetical belief, under this condition, about the consequent." According to Stalnaker's hypothesis (Harper, 1981, p. $11)$, then, the credence, $\mathrm{C}$, that we grant to a conditional of the form ' $a \rightarrow c$ ' should be the same as the ascribed conditional probability, $\mathrm{P}$, of its consequent given the antecedent, $\mathrm{P}(c \mid a)$.

$$
\begin{aligned}
& \text { Stalnaker's Hypothesis } \\
& \mathrm{C}(a \rightarrow c)=\mathrm{P}(c \mid a)
\end{aligned}
$$

The second distinguishing feature of Stalnaker's interpretation is that in situations where a conditional's antecedent is not satisfied, the conditional does not lack a truth-value - rather its truthvalue is indeterminate. In some cases it is true, in others false, depending on factors that are not referenced by the conditional. Specifically, the truth-value of a Stalnaker conditional with a false antecedent depends on the proximity of the state of affairs it describes to the actual world. If the described state of affairs more closely resembles a world where the antecedent and consequent obtain together, then the conditional is true. Alternately, if it describes a world closer to one where the antecedent is true but the consequent false, then the conditional is false. Thus, while the material conditional is extensional-i.e., it is truthfunctional and can be understood as depending only on stated conditions pertaining to the actual world-Stalnaker's conditional is intensional - depending instead on unstated conditions pertaining to the proximity of various possible worlds to the actual one. For just this reason, Stalnaker's conditional is also called the non-truth-functional interpretation of indicative conditionals. If this interpretation is correct, then the semantics of many conditional sentences is properly given by truth-at-world conditions, rather than truth conditions.

\section{Extant approaches to DA and AC}

Both the problems with and our inclination to infer by DA and AC were already known to Aristotelian scholarship:

The refutation which depends on the consequent arises because people suppose that the relation of consequence is convertible. ... [S] ince after rain the ground is wet in consequence, we suppose that if the ground is wet, it has 
been raining; whereas that does not necessarily follow. (Aristotle, Sophistical Refutations, 167b1 ff.; cf. Hansen and Pinto, 1995, p. 25)

This passage identifies the prevailing explanation of our reliance upon DA and AC, namely our tendency to treat the relation of consequence expressed in the conditional as reversible or "convertible" (Floridi 2009, p. 398; see Sect. 7 below). ${ }^{6}$ As it were, while $a \rightarrow c$ is asserted, we allegedly parse the utterance as if the converse $c \rightarrow a$ had also been asserted. But why do we tend to treat this relationship as convertible? This question leads to the interpretive strategies for legitimating our ostensibly DA and AC inferential practices. Such strategies generally try to explain away what would otherwise be paradigmatic instances of fallacious deductive inference by citing aspects of our linguistic behavior.

\subsection{Interpretive strategies}

A first interpretive strategy is descriptive and begins with observations about our ordinary reasoning habits, dispositions, and practices. Then several moves are available.

First among these is the recognition that many ordinary and perfectly acceptable uses of conditional expressions do not in fact assert conditional sentences. Consider the old example:

\footnotetext{
${ }^{6}$ We take convertible to mean that the converse of the stated conditional is treated as also asserted. Equivalently, following Adler (1994, p. 227) and Moldovan (2009, pp. 323-234), we take reversible to mean that the terms of the stated conditional may be reversed thereby yielding the converse of the stated conditional.

We rely on standard terms to denote such relations. Given an original expression where $a$ and $c$ are related such that $a \rightarrow c$ or $\mathrm{P}(c \mid a)$, respectively, then

(i) $c \rightarrow a$ and $\mathrm{P}(a \mid c)$ denote the conversion of this relation (or 'the converse'): the relata change places and maintain their truth values; and

(ii) $\sim a \rightarrow \sim c$ and $\mathrm{P}(\sim c \mid \sim a)$ denote the inversion ('inverse'): the relata maintain place and change truth values; and

(iii) $\sim c \rightarrow \sim a$ and $\mathrm{P}(\sim a \mid \sim c)$, finally, denote the obversion ('obverse'): the relata change both places and truth values. (Logicians tend to call the obverse the 'contrapositive'.)

Finally, we refer to a proposition's negation as 'the complement,' e.g., $\sim a$ is the complement of $a$, and $1-\mathrm{P}(a)$ is the complement of $\mathrm{P}(a)$.
}

(C) David Godden and Frank Zenker. Informal Logic, Vol. 35, No. 1 (2015), pp. 88-134. 


\section{Cold beer}

"There's beer in the fridge, if you're thirsty," your welcoming host offers.

You are thirsty.

Ergo, there's beer in the fridge!

This is clearly an abysmal inference, but not because of its form which seems to validly affirm the antecedent. Rather, the error occurs when the offer of beer is mistakenly interpreted as an assertion of enabling conditions for having a cold one. Recognizing this, we needn't worry that some (apparent) instances of modus ponens are abysmal.

Another descriptive move asserts an ambiguity in language that would license both deductively valid and deductively invalid interpretations of the reasoning involved. For example, Fearnside and Holther (1959, p. 156; cf. Horn, 2000, p. 294) claim that "In common speech there is the ambiguity of 'if', which may mean simply 'if' or may mean "if and only if.", An alternative, here, is to adopt a psychologistic stance on the relationship between our ordinary reasoning proclivities and the standards or norms that ought to govern them (cf. Stein 1996, pp. 231 ff.). Pelletier and Elio (2005, p. 20), for instance, argue that "deductive reasoning has a 'normative standard' that is 'external' to people whereas default reasoning has no such external normative standard.... Here there is no external standard of correctness other than what people actually infer." So our untutored reasoning performance may be taken to mark not only competence norms but the very rational standards underlying these performances.

A second interpretive strategy additionally relies on a normative principle of charity to prize non-fallacious but unarticulated interpretations of stated arguments over those that are invalid yet directly asserted. For example, Burke's (1994, p. 24) fairness principle, according to which "we [should] not presume the presence of fallacy," prescribes that we should always prefer non-fallacious to fallacious interpretations "unless the balance of textual, contextual, and other evidence" favors the fallacious interpretation. Consider the example:

\footnotetext{
${ }^{7}$ Woods (2013, pp. 384-385) considers a similar account of a putatively "not infrequent" hyperconditional use of 'if ... then' as expressing a biconditional relationship, noting an ecological demand that we reliably ascertain and track relations of, particularly causal, consequence.
} 


\section{DA Capital punishment}

If capital punishment deterred murder $(a)$, it would be justified $(c)$.

Since it doesn't $(\sim a)$, it isn't $(\sim c)$.

Burke (pp. 24-25) claims that fairness allows us to attribute to the arguer the converse, $c \rightarrow a$, of the stated conditional, $a \rightarrow c$, and to interpret her reasoning as a valid, enthymematic instance of modus tollens. (Equivalently, one might attribute to the arguer the inverse, $\sim a \rightarrow \sim c$, of the stated conditional and interpret her reasoning as a valid, enthymematic instance of modus ponens.) Burke proposes that the stated conditional has a dialectical, rather than premissary, role of "making clear that the arguer opposes capital punishment only because the arguer believes it doesn't deter murder."

As Adler (1994, pp. 273-274) observes, since so much of our arguing is highly but appropriately enthymematic (for reasons of both communicative considerateness and cognitive economy), non-fallacious interpretations of apparently fallacious arguments are almost always easily within reach. According to Burke, the upshot is that fallacious reasoning is in fact infrequent and what can appear as faulty reasoning is often perfectly cogent when charitably interpreted.

Charitable approaches to fallacy remediation, however, are typically subject to criticism on both descriptive and normative grounds. As Godden and Walton (2004, p. 227) note, Burke's interpretation does not seem to satisfy his own principle of fairness, since

there seems to be plenty of textual evidence to suggest that the arguers in these [Burke's] cases are asserting the stated conditionals, while the only evidence to suggest that they are asserting the inverse conditional is provided by a normatively driven principle of charity.

Their claim is that putatively charitable principles of reconstruction are not purely hermeneutic if they presuppose a standard of rational goodness that is imported into the argumentative situation under analysis. A purely hermeneutic principle of charity would rather seek empirical evidence from what the arguers themselves say and do to determine the norms that these arguers take themselves to be committed to or to have adopted. 
This leads to a more general descriptive problem with charitable approaches. As Adler (1994, p. 275) writes:

An indication that there is something often illicit about these non-fallacious alternatives ... is that they are generated only after the fallacy accusation has been made. Thus, they are formulated with a prior agenda in mind. Rather than being responsive solely to matters of comprehension, they are constructed just to fit the case at hand.

This suggests that charitable approaches are not genuinely interpretive. Worse, as Adler (p. 274) observes, the availability of non-fallacious interpretations alone does not justify our attribution of some such interpretation to the arguer. Specifically, the observation that we treat conditionals as convertible does not show that speakers make valid inferences using some hearersupplemented premise, rather than make invalid inferences using their stated premises. As Adler (p. 277) claims, "[t]he attribution must then correspond to reasoning in the mind of the person criticized." But this would require data that charitable approaches tend not to invoke, perhaps because it is typically unavailable.

Finally, a normative problem also arises because "it is no genuine improvement in an argument to secure a better relation between premises and conclusion by introducing any assumption, even if the weakest requisite, that is unsupported" (Adler, p. 275). This claim is amplified by Stone (2012) who points out the following: the same evidential considerations that would undermine the original invalid argument can be used to show the unacceptability of the supplemented premise that is employed to interpret the argument as valid. Combining Adler's and Stone's objections yields the following: since the unstated, and perhaps unsupported, premise is supplied in order to repair ostensibly defective reasoning, this reasoning would be presumptively unacceptable. Stone (p. 237) therefore concludes that "strengthening the conditional in arguments that deny the antecedent does not do the logical work that these interpreters assume that it does." Indeed, such interpretive strategies not only fail to remedy the very problem they set out to solve; they also incur a rather high explanatory cost by collapsing a distinction well-worth preserving, namely between a complete but invalid argument 
with well-supported premises and an incomplete but valid argument with at least one unsupported premise. ${ }^{8}$

A third interpretive approach, which might be called explanationist, applies to a limited subset of seemingly DA and AC structures, and reads them as having an explanatory rather than an evidential function. For example, Salmon (1984, p. 132) observes that, on a hypothetico-deductive account of scientific theories, hypothesis confirmation seems to have the following inferential structure: "If hypothesis, then prediction. Prediction [is observed to be true]; therefore hypothesis [is inferred to be true]." He notes that this crude reconstruction of hypothesis confirmation is deductively invalid (p. 132ff.), but that a more robust reconstruction - one that takes account of alternative explanatory hypotheses and their relative prior probabilitiesinstantiates an inference to the best explanation, which is inductively cogent (p. 137). Second, Hitchcock (1995) supplies an interpretation on which some arguments having the apparently fallacious DA form 'Every $\mathrm{G}$ is $\mathrm{H}$. Because $a$ is not $\mathrm{G}, a$ is not $\mathrm{H}^{\prime}$ may in fact be instances of modus tollens. So long as the initial conditional premise is interpreted as expressing a sufficient causal, rather than an evidential, condition, Hitchcock suggests that the argument may be read as an enthymematic statement of the argument: 'Every $\mathrm{G}$ is $\mathrm{H}$. $a$ is not $\mathrm{H}$. Therefore $a$ is not $\mathrm{H}$ because $a$ is not G' (p. 299). By supplementing the stated argument with the premise ' $a$ is not $H$ ' the hidden structure of this argument becomes one of denying the consequent (rather than the antecedent), and the initial argumentative text states an explanatory condition rather than an evidential one. One can readily agree with this explanation, but should nevertheless note that these interpretative moves do nothing to rehabilitate DA and AC arguments per se. When viewed as reconstructive moves, moreover, they remain susceptible to the same general problems as the other interpretive strategies already discussed.

Rather than assume that any logical work is done when conditionals are treated as convertible, a range of pragmatic approaches have been developed for the same explanatory purpose. We now turn to these.

\footnotetext{
${ }^{8}$ Such considerations have led some theorists away from charity as an interpretive principle. For instance, Paglieri and Woods (2011a) argue that there may be other (and better) redemptive strategies than charity and that enthymematic argumentation is best interpreted with a principle of parsimony not charity, concluding (2011b) that argument interpretation should not be viewed as a reconstructive process. Similarly, Lewiński (2011) argues that charity produces an interpretive inequity in dialectical contexts.
}

(C) David Godden and Frank Zenker. Informal Logic, Vol. 35, No. 1 (2015), pp. 88-134. 


\subsection{Pragmatic grounds for conditional perfection}

Geis and Zwicky (1971, p. 562) coined the term conditional perfection for a "tendency of the human mind ... to "perfect conditionals to biconditionals" such that "[a] sentence of the form $a \supset c$ [after being perfected to yield $(a \supset c) \&(c \supset a)$ invites an inference of the form $\sim a \supset \sim c$ " (notation adapted). Using the example:

(1) If you mow the lawn, I'll give you five dollars,

they (p. 562) claim that the utterance of (1) invites the inverse inference that (2):

(2) If you don't mow the lawn, I won't give you five dollars.

They proceed (p. 565) to argue that "what we have called invited inferences constitutes a special class of [Gricean] implicatures," and claim that the invited inferences involved in conditional perfection are hence justified unless the hearer has reason to think otherwise.

While not being logical in character, pragmatic considerations do regularly justify our inferences. For example, a speaker's assertion that $p$ normally gives a hearer sufficient reason to infer that the speaker believes $p$, even though there is no logical contradiction in supposing otherwise. Sentences of the form ' $p$, but I don't believe that $p$ ' are consistent, yet their utterance results in a performative inconsistency known as Moore's paradox.

Similarly, assertions like (1) implicate sentences like (2) (van der Auwera, 1997a, 1997b; Horn, 2000). Here's how. Consider propositions of the following forms ordered on a scale such as:

\section{Scale of implication and implicature}

If $p, q$ and if $r, q$ and if $s, q$

If $p, q$ and if $r, q$

If $p, q$

Implication flows down this scale. Because any proposition on the scale entails all below it, the higher up the proposition sits, the more informative it is. By contrast, implicature flows up the scale: assertion of some proposition on the scale conversationally implicates the falsity of all propositions sitting higher on the

(C) David Godden and Frank Zenker. Informal Logic, Vol. 35, No. 1 (2015), pp. 88-134. 
scale. Presuming that Grice's $(1989$, p. 26) maxim of quantity"make your contribution as informative as required (for the purposes of the exchange)"-is followed, asserting a proposition lower on the scale thus implicates that the speaker was not in a position to be more informative, that is, she could not have truthfully asserted any proposition higher on the scale. Such assertions then invite the inference that propositions higher on the scale are false.

This has come to be called scalar conversational implicature (SCI) and is taken to pragmatically justify conditional perfection. One is invited to infer that all conversationally relevant, unstated sufficient conditions do not apply. Hence, the stated sufficient condition is implicated to also be necessary, thereby strengthening the asserted conditional to a biconditional (van der Auwera, 1997a, p. 197). Previously, Strawson had attributed such inferences to "a 'pragmatic' consideration, a general rule for linguistic conduct ... that one does not make the (logically) lesser, when one could truthfully (and with equal or greater linguistic economy) make the greater, claim" (Strawson, 1952, p. 179; cf. Horn, 2000, p. 305).

Finally, Moldovan (2009, pp. 318 ff.) observes that so long as conditional perfection can be pragmatically justified by SCI, then inferences that apparently and fallaciously deny the antecedent or affirm the consequent will be valid in just these cases. This makes such pragmatic accounts ultimately normative, distinguishing valid from fallacious instances of (ostensibly) DA or AC reasoning, although the relevant distinguishing features are to be found through interpretive pragmatic considerations.

\subsection{Normative, dialectical approaches}

In contrast to interpretive approaches, Godden and Walton (2004) offer a normative, dialectical approach that specifies an argumentative context in which, they claim, denying the antecedent is cogent. The relevant context is dialectical: an opponent rejects a conclusion (advanced by a proponent) by denying the antecedent of the proponent's modus ponens inference. Here, DA functions as premise denial.

When used in this way, Godden and Walton claim, DA is a legitimate argumentative move, although its characteristics set it apart from standard deductive inference. They specifically treat DA as a rebuttal, or a counter-argument, that cannot without further ado be used to establish claims. Godden and Walton thus agree with standard accounts that

(C) David Godden and Frank Zenker. Informal Logic, Vol. 35, No. 1 (2015), pp. 88-134. 


\section{$\left(\mathrm{DA}_{\mathrm{F}}\right) \quad a \supset c, \sim a \mid-\sim c$}

is a fallacious form of argument. By contrast, they claim that "[t]he conclusion of the counter-argument is not that we should accept not $C$, but rather that we should not accept $C$ for the reasons given in the initial conditional argument" (p. 239, emphasis in original). Thus, they (p. 232) propose legitimate applications of DA to have the following form:

$$
\left(\mathrm{DA}_{\mathrm{L}}\right) \quad a \supset c, \sim a \mid \neq c
$$

where $\mid \neq$ is read as 'from which it does not follow that'. Although they claim that $\mid \neq c$, which is neither a theorem nor a commitment, "does not have any logical consequences whatsoever" (p. 232) (e.g., it cannot be used as a premise in further argument), $\mathrm{DA}_{\mathrm{L}}$ as a form of argument nonetheless has both an epistemic and a dialectical effect.

Its epistemic effect is to show the unacceptability of some claim, $c$, on the basis of a specific but unacceptable reason, $a$. Its dialectical effect is twofold: (i) it requires either that $c$ not be admitted, or that it be retracted as a commitment in the argumentative dialogue; (ii) it compels the proponent to find another sufficient reason for $c$ in order to advance her case. Overall, $\mathrm{DA}_{\mathrm{L}}$ has an argumentative effect similar to that of presumptive argument, namely shifting the burden of proof, here from the opponent back to the proponent.

\subsection{Defeasible retraction contexts}

Similarly, Woods (2013, pp. 253-254) demonstrates how something resembling denying the antecedent can legitimately occur in defeasible retraction contexts when new information is added to a premise set which occasions (i) the denial of an antecedent (that, in this case, is some member of an initial premise set), together with (ii) the retraction of a consequent (in this case, a defeasible consequence of the initial premise set). Woods adds that, properly speaking, this is not a case of denying the antecedent because the consequent is not given up on the basis of denying of the antecedent. Rather, the consequent is retracted because the consequence relation between the antecedent premise set and the consequent conclusion has been severed. 


\section{The fallaciousness of DA and AC: The preliminary case}

Having reviewed extant treatments we now provide a preliminary case for the fallaciousness of DA and AC arguments on any prevailing interpretation of indicative conditionals, beginning with their interpretation as material conditionals. In doing so we begin to identify those conditions that tend to remain unstated in DA and AC arguments, but on which their cogency in fact depends.

It is well-known that, DA and AC being formally invalid (see Godden and Walton 2004, pp. 220-223), adding DA and $\mathrm{AC}$ to the repertoire of acceptable inference-licenses is ruinous to a logical system. ${ }^{9}$ This, though, needn't show that DA and $\mathrm{AC}$ arguments are fallacies in the sense that they conspicuously fail to provide adequate reasons for their conclusions. Generally, a cogent argument explicitly cites as reasons the conditions on which the acceptability of its conclusion depends. But with DA and $\mathrm{AC}$ arguments more is involved than the antecedent's falsehood or the consequent's truth. This is best appreciated visually and at the same time serves to move our discussion towards probabilities.

Following Sanford (2003, pp. 93-100), let a unit line represent the total probability space and divide the line such that the proposition $\phi$ and its complement $\sim \phi$ fill two regions proportional in size to their respective probability. ${ }^{10}$ The resulting partition visually represents the relative probability of the propositions (Fig. 1). ${ }^{11}$

${ }^{9}$ Consider, for example, the following derivation:

(1) $(a \& \sim a) \supset(a \vee \sim a)$ (A theorem of the propositional calculus)

(2) $a \vee \sim a \quad$ (Another theorem, the bivalence principle)

(3) $a \& \sim a \quad$ (1,2 AC)

${ }^{10}$ Limit cases occur when $\phi$ is a logical truth, thus occupying the entire probability space, and when $\phi$ is a logical falsehood so that $\sim \phi$ occupies the entire probability space.

11 Sanford introduces this visualization by adapting a method employed by Adams (1975, pp. 9-11) where modified Venn-diagrams represent probabilities within a universe (or domain of discourse). The areas circumscribed are proportional to the probability of the conditions demarcated. Edgington (1995, pp. 261 ff.) and Jeffrey (2004, pp. 10-11) similarly employ a box diagram. 


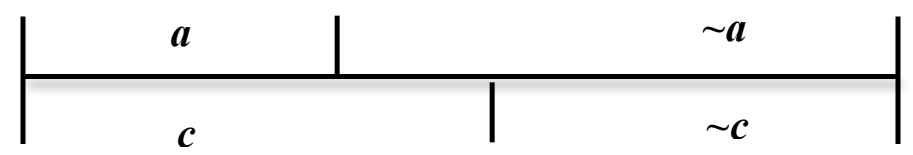

Figure 1. Unit line showing two propositions $(a, c)$ and their logical complements $(\sim a, \sim c)$ partitioned proportionally to the relative probability of each.

Because a material conditional $a \supset c$ only excludes $a \& \sim c$, the $a$ region must be properly contained within the $c$-region (as in Fig. 1). So the conditional is false only in situations like in Fig. 2.

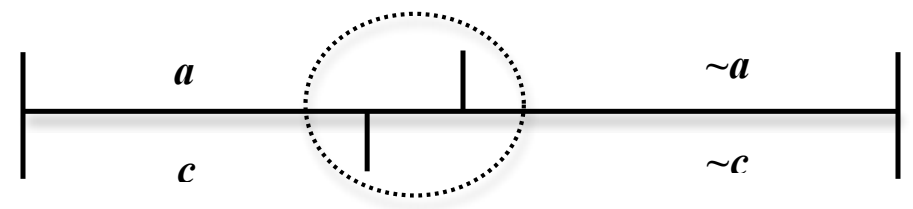

Figure 2. $a \supset c$ is false since the $a$-region exceeds the $c$-region (as indicated by the circle).

The material conditional makes no claims about: (i) the size of the $a$-region relative to its complement, (ii) the size of the $c$ region relative to its complement, nor (iii) the proportion of the $c$-region occupied by the $a$-region. The material conditional only claims that the $a / \sim a$ partition must fall within the $c$-region or coincide with the $c / \sim c$ partition.

It is easy to see that the cogency of DA and AC arguments depends entirely on independent matters that further qualify this containment relation. ${ }^{12}$ Cogency increases to the extent that the $a / \sim a$ partition lines up with the $c / \sim c$ partition, as indicated by the arrows in Fig. 3.

${ }^{12}$ Recall our use of the term 'cogent' to mean well-reasoned (see fn.1). Granting that DA and AC are deductively invalid forms of argument, we allow that there can, nevertheless, be cogent, yet invalid forms of argument. Some invalid arguments have more probative merit than others, and sometimes the degree of probative strength provided by an invalid argument can meet some situationally appropriate standard of evidence (Godden, 2005). We proceed to explore the cogency of DA and AC arguments by detailing the conditions on which their probative merits depend.

(C) David Godden and Frank Zenker. Informal Logic, Vol. 35, No. 1 (2015), pp. $88-134$. 


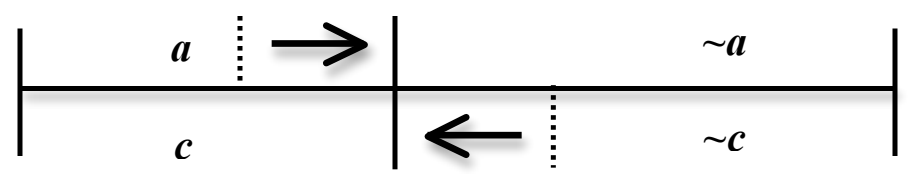

Figure 3. DA and AC arguments becoming more cogent as partitions line up.

To the extent that the $a / \sim a$ and the $c / \sim c$ partitions coincide, the converse conditional $c \supset a$ will also be true. In such cases, DA and $\mathrm{AC}$ deny necessary and affirm sufficient conditions, respectively, and their cogency is thereby explained.

However, the incompatibility of a true antecedent with a false consequent is also satisfied when the separation between the $a / \sim a$ and the $c / \sim c$ partitions is vast. DA and AC are now obviously invalid, as is apparent from inspecting the partitions in Fig. 4.

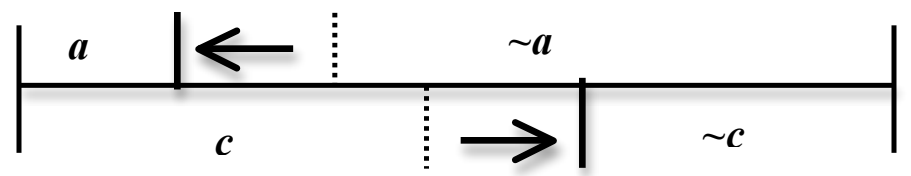

Figure 4. DA and AC arguments becoming more fallacious.

The probative weight of denied antecedents and affirmed consequents thus depends on conditions not asserted by the conditional. Therefore, DA and AC arguments as stated are not probative - they fail to provide reasons for their conclusions - unless such assumptions are explicated and met. In order to responsibly rely upon and to properly assess the cogency of DA and AC arguments, these extrinsic factors should not only be satisfied in fact but then should also be explicitly stated in the (reconstructed) argument.

The relevant information, however, tends to be drawn from background knowledge. For example, consider the true conditional:

(3) If something is an orchid, then it is a plant.

The merits of DA or AC arguments using (3) vary depending on whether the universe of discourse (or the context of discussion) is limited to the flowerage in an orchid show or all the fauna in nature. This applies equally to conditionals that do not involve quantification. For example:

(C) David Godden and Frank Zenker. Informal Logic, Vol. 35, No. 1 (2015), pp. $88-134$. 
(4) If its battery is dead, the car won't start.

Here, the merits of DA or AC arguments using (4) will vary depending on a host of conditions constituting the general mechanical condition of the car.

\subsection{Weakening the conditional}

We now proceed to interpretations on which indicative conditionals are weaker than the material conditional and argue that weakening the conditional to a defeasible, probabilistic or plausibilistic one alone does not improve the case for DA and AC.

A defeasible conditional merely refrains from asserting a fully sufficient/necessary relationship between its antecedent and consequent conditions; its meaning therefore amounts to an unspecific, partial exclusion of true antecedents with false consequents. So while the $a$-region is normally (or mostly) contained within the $c$-region, a defeasible conditional allows for exceptional (or excepting, or a minority of) cases in which $a$ can occur within the $\sim c$ region, as in Fig. 5.

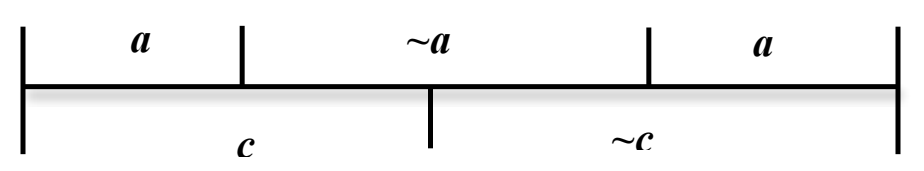

Figure 5. Weakened conditional.

Conditionals weakened by defeasibility not only make modus ponens and modus tollens "risky" inferences, they do not support DA and AC inferences either. Here again, DA and AC arguments are not probative when their merits are taken as based only on their stated claims. Whatever our tolerance for inferential risk, the cogency of a DA or AC argument with true premises will minimally depend on the extent of the coincidence between the $\sim a$ and $\sim c$ conditions, or the $c$ and $a$ conditions respectively. Yet both of these factors are not asserted by, and indeed remain independent of, the stated premises of DA and $\mathrm{AC}$ arguments.

Worse still is to interpret the conditional suppositionally such that cases where the antecedent is not satisfied are excluded. Suppositional conditionals still assert that for all cases where the antecedent is satisfied so is the consequent, as in Fig. 6 (cf. Edgington, 1995, p. 264).

(C) David Godden and Frank Zenker. Informal Logic, Vol. 35, No. 1 (2015), pp. 88-134. 


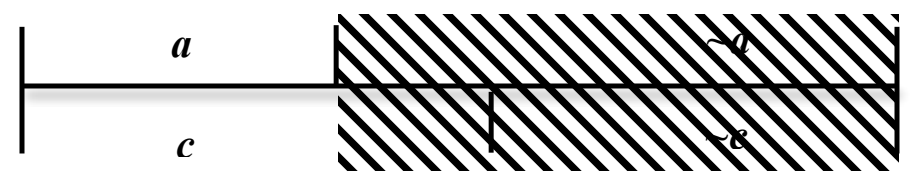

Figure 6. Suppositional interpretation, where the shaded area indicates cases excluded by supposition.

Here, no inferences are licensed when the antecedent is denied. Also AC arguments are problematic because the conditional is only invoked, or applicable, when its antecedent obtains. Hence, affirming the consequent becomes trivially valid rather than probative. In this case, then, it is not that DA and AC arguments fail to be probative; rather they are entirely inept.

Stalnaker conditionals fare no better in this. Given their intensional semantics in cases where their antecedent is false, their truth-value in these cases also depends entirely on factors not referenced by the conditional, specifically on the relative proximity of the world envisaged by the conditional to an actual world where either both the antecedent and consequent obtain, or to one where only the antecedent obtains but not the consequent. Hence, the ability to make a DA inference with a Stalnaker conditional-let alone its cogency-depends on conditions not stated in the argument. Similar problems beset AC arguments made with Stalnaker conditionals. On extensional valuations (where the antecedent is true), AC inferences are trivially valid. On intensional valuations (where the antecedent is false), as with DA inferences, the truth of the conditional depends on factors not referenced by the conditional itself.

In sum, it must be granted that DA and AC are formally invalid patterns of argument. Based on the case just made, we take it to be (presumptively, at least) established that DA and $\mathrm{AC}$ arguments are prima facie incogent on non-deductive, defeasible, suppositional, and intensional interpretations of the conditional also. Generally, DA and AC arguments fail to cite among their premises the conditions on which the truth of their conclusions properly depends, that is, they fail to give reasons. We now consider whether recent probabilistic treatments can improve this case. 


\section{Recent probabilistic treatments}

Recent scholarship presents DA and AC arguments as probative, even cogent, in probabilistic contexts. We will first review an argument by Stone (2012) and in the following section turn to Floridi (2009).

Stone takes DA arguments to have force well beyond undermining an opponent's position.

The premises of an argument that denies the antecedent ... can have the logical force of an inductive argument, meaning that if the premises are true the conclusion probably follows. In undermining the opponent's position this form of argument provides reasons for believing that the position is false. ... Denying the antecedent is a legitimate and effective inductive argument strategy. (Stone, p. 329, italics added)

In reviewing this case, we point to complexities that remain under-described by the verb 'can', above. On Stone's view, DA arguments may have probative weight, albeit probabilistically, so that one could allegedly use them to establish claims.

Whereas they [Godden and Walton, 2004] maintain that the force of this type of argument [i.e., a DA argument] is only that we should not accept the conclusion $C$ for the reasons given in the initial conditional argument, I think its force is that we should probably accept not $C \ldots$ In other words, I think that denying the antecedent has inductive strength. (Stone, p. 343). ${ }^{13}$

Stone offers three supporting arguments for his claim. We briefly address the first and engage with the third at some length. The second (pp. 346-348) — which invokes work by Floridi (2009)

13 Stone equates rejecting a claim $c$ with (probably) accepting its logical complement non c, whereas Godden and Walton, as we saw in Sect. 3.3, take rejecting $c$ to be consistent with either accepting non $c$ or with taking no position. They claim that DA can be used legitimately as a way of withdrawing commitment from, or denying commitment to, a claim and thereby rejecting it.

Stone writes: "If denying the antecedent can be a legitimate argumentative strategy to reject a position, then it follows that it can be used to establish the improbability of a position" (p. 343). This claim is in need of qualification (see below). For instance, skeptical arguments may serve to reject claims without establishing any.

(C) David Godden and Frank Zenker. Informal Logic, Vol. 35, No. 1 (2015), pp. 88-134. 
who presents $\mathrm{AC}$ and DA as "quick and dirty" Bayesian inferences or bets on probabilities values - is taken up in Section 6.

\subsection{Converse conditionals again}

Stone's first argument (pp. 343-346) relies on insights already considered above. As we saw, adding a converse conditional to a fallacious DA argument repairs it, thus making the inference valid. But as Stone reminds us, the same evidential considerations that would defeat the initial DA inference-thus showing it to be invalid-will also show the supplemented, converse conditional to be false. Evidentially, then, the initial DA argument cannot be worse off than the reconstructed modus tollens argument. Hence, if the repaired argument is a good one, as the standard view has it, so is the initial DA argument.

Stone's insight is correct but it fails to support his conclusion. On the standard view, repairing a fallacious DA argument by adding its converse conditional makes the argument valid rather than cogent. After all, argument cogency requires both acceptable patterns of reasoning and acceptable premises. But just as the validity of the initial invalid inference relied on material not expressed in it, the cogency of the repaired argument also relies on an unsupported and presumptively unacceptable premise. $^{14}$

As Stone (rightly) points out, adding the converse conditional only relocates but does not resolve any underlying problem with the initial argument. His critical claim is that interpretive approaches to repair DA arguments are normatively ineffective because they fail to resolve evidentiary defects in the initial argument. But this insight hardly suffices to establish DA reasoning as cogent. Rather, it serves to stress that the cogency of DA arguments and their reconstructed surrogates stand or fall together and depend on considerations not articulated in either. Moreover, it is already widely recognized that DA arguments, being invalid, can be cogent given that their converse condition-

\footnotetext{
14 Stone's argument does not pose a serious objection to Godden and Walton's (2004) normative dialectical approach, or to Moldovan's (2009) normative pragmatic approach. After all, the former does not ascribe the inverse conditional to a speaker in order to repair an ostensibly fallacious argument. And the latter licenses DA or AC only when there are pragmatic grounds to take the inverse conditional to be true and the speaker to be committed to it, namely when conditional perfection is pragmatically licensed by scalar conversational implicature (see Sect. 3.2).
}

(C) David Godden and Frank Zenker. Informal Logic, Vol. 35, No. 1 (2015), pp. 88-134. 
als are true (i.e., when the conditions being stated as sufficient are also necessary). As the issue is whether our habit of treating conditionals as convertible is ever rational, treating that habit as evidence for its own rationality begs the question.

\subsection{Stone's total evidence argument}

Stone's third argument (pp. 348-349), the total evidence argument, claims that treating DA merely as a form of refutation or counter-argument, à la Godden and Walton (2004), undervalues its probative merits. Stone holds (correctly) that DA can be used not only to refute claims but also to support their logical complements, albeit probabilistically. So just as, according to modus ponens, the truth of an antecedent counts towards the truth of its consequent, according to the principle of total evidence the inverse also holds: the falsity of an antecedent should count towards the falsity of its consequent.

The probability that one of my beliefs is true is based on the body of evidence that I have to support it. Notice, furthermore, that it [my belief] is made more probable by additional evidence. In the same way in which adding true beliefs makes the claim they support more probable, subtracting beliefs that have been found false makes the claim less probable in relationship to the overall body of evidence. (p. 348)

Stone concludes:

From an epistemic point of view, it is reasonable to conclude that denying the antecedent has inductive strength. It captures the way in which diminishing the body of evidence on which a claim is based makes the claim less probable. Where $\mathrm{C}$ is a claim which has been supported by some reasons, the force of denying the antecedent is not only that we should not accept the conclusion $C$ for the reasons given in the initial argument, but that we should probably accept not $C$. (p. 350)

The total evidence argument, of course, can only apply to nondemonstrative inferences. After all, if deductive validity is demanded as a standard of evidence, then DA and AC are plainly invalid. The semantics of the material conditional, as we have seen, stipulates that the falsity of an antecedent is compatible (i.e., consistent) with either the truth or the falsity of its consequent, and similarly that the truth of a consequent is compatible with either the truth or the falsity of its antecedent. So DA and

(C) David Godden and Frank Zenker. Informal Logic, Vol. 35, No. 1 (2015), pp. 88-134. 
$\mathrm{AC}$ arguments cannot generate informative deductive consequences.

\subsection{Evaluating the total evidence argument}

To evaluate Stone's argument in probabilistic evidential contexts, recall that a conditional ordinarily asserts the incompatibility of the truth of its antecedent, $a$, with the falsehood of its consequent, $c$, under some appropriate modality. We can ignore trivial cases where this incompatibility is due to a logically true consequent or a logically false antecedent, which only leaves cases where $a$ and $c$ are contingent.

Suppose then that $a \rightarrow c$ is interpreted probabilistically. Moreover, suppose the weakest possible proponent commitment in this context: namely, that $a$ provides some support to $c$, as expressed in (5), where $\mathrm{P}_{\mathrm{i}}(c)$ marks the initial or prior probability, and $\mathrm{P}_{\mathrm{f}}(c)$ marks the final or posterior probability.

(5) $\mathrm{P}_{\mathrm{f}}(c)=\mathrm{P}_{\mathrm{i}}(c \mid a)>\mathrm{P}_{\mathrm{i}}(c){ }^{15}$

When probabilistic support is measured over the closed interval from 0 to 1 , a degree of support for some proposition $\phi$ entails the degree of support for its complement via $\mathrm{P}(\phi)=1-\mathrm{P}(\sim \phi)$. Moreover, $\mathrm{P}_{\mathrm{i}}(c \mid a)$ is given by the principle of conditionalization (PC), that is, the definition of conditional probability:

$$
\text { (PC) } \mathrm{P}_{\mathrm{i}}(c \mid a)=\mathrm{P}(c \& a) / \mathrm{P}(a)
$$

Since $\mathrm{P}(c \& a)=\mathrm{P}(a \mid c) \mathrm{P}(c), \mathrm{PC}$ yields Bayes' theorem $(\mathrm{BT})^{16}$ to which we return in Sect. 6. Now dropping the subscripts, BT comes in two equivalent versions.

\footnotetext{
${ }^{15}$ (5) says that the final or posterior probability of $c, \mathrm{P}_{\mathrm{f}}(c)$, equals the conditional probability of $c$ given $a, \mathrm{P}_{\mathrm{i}}(c \mid a)$, and that the latter is greater than the initial $(\mathrm{i})$ or prior probability of $c, \mathrm{P}_{\mathrm{i}}(c)$, which is the probability of $c$ before and independently of having considered the probability of $a$. This inequality characterizes the probability of $a$ as being positively relevant to that of $c$, so that the former can confer support upon the latter. But (5) leaves open the exact degree or extent of such support; one of its measures, $\mathrm{S}(c \mid a)$, can be defined as: $\mathrm{S}(c \mid a)=\mathrm{P}_{\mathrm{i}}(c \mid a)-\mathrm{P}_{\mathrm{i}}(c)>0$ (Korb, 2003, p. 44; cf. Howson and Urbach, 1993, p. 117, notation adapted).

${ }^{16}$ One reaches $\mathrm{BT}^{*}$ by substitution in $\mathrm{BT}$, since $\mathrm{P}(a)=\mathrm{P}(a \mid c) \mathrm{P}(c)+\mathrm{P}(a \mid \sim c) \mathrm{P}(\sim c)$.
} 


$$
\begin{array}{ll}
\text { (BT) } & \mathrm{P}(c \mid a)=[\mathrm{P}(a \mid c) \mathrm{P}(c)] / \mathrm{P}(a) \\
\left(\mathrm{BT}^{*}\right) & \mathrm{P}(c \mid a)=\mathrm{P}(a \mid c) \mathrm{P}(c) /[\mathrm{P}(a \mid c) \mathrm{P}(c)+\mathrm{P}(a \mid \sim c) \mathrm{P}(\sim c)]^{17}
\end{array}
$$

According to Stone, "subtracting beliefs that have been found false [i.e., our $\sim a$ ] makes the claim [our $c$ ] less probable in relationship to the overall body of evidence" (p. 348). With mere retraction, the support for $c$ can, in the absence of $a$, only depend on the prior probability $\mathrm{P}_{\mathrm{i}}(c)$. So if conditionalization on $a$ results in $\mathrm{P}_{\mathrm{i}}(c \mid a)>\mathrm{P}_{\mathrm{i}}(c)$, as stated in (5), then retracting $a$ leaves the support for $c$ at the prior value, $\mathrm{P}_{\mathrm{i}}(c)$. (This is what Walton and Godden's claim in Sect. 3.3 amounts to when expressed with probabilities.) Stone, however, is concerned not with retraction but with subtraction of $a$, i.e., conditionalization on $\sim a$. So he would be committed to (6), which we call Stone's total evidence thesis:

$$
\left.\mathrm{P}_{\mathrm{f}}(\sim c)=\mathrm{P}_{\mathrm{i}}(\sim c \mid \sim a)>\mathrm{P}_{\mathrm{i}}(\sim c)\right)^{18}
$$

Already in genuinely probabilistic contexts, where $0<\mathrm{P}(\phi)=1-\mathrm{P}(\sim \phi)<1$, the inequalities in (5) and (6) do, of course, depend on suitable probability values. But these values need not be unproblematically available in a given natural language context. ${ }^{19}$ At any rate, (5) and (6) do not express general truths

${ }^{17} \mathrm{P}(a \mid c)$ and $\mathrm{P}(a \mid \sim c)$ express likelihoods, namely the probability of $a$ given $c$, and the probability of $a$ given $\sim c$, respectively. $\mathrm{P}(a \mid c)$ can be read as the impact of $a$ on $\mathrm{P}(c) . \mathrm{P}(a \mid \sim c)$ is also known as the false positive rate. To express modus ponens with $\mathrm{BT}$, if $a \supset c$ is true, then $\mathrm{P}(c \mid a)=1$. So the rate of exceptions, $\mathrm{P}(\sim c \mid a)$, is zero because $\mathrm{P}(c \mid a)=1-\mathrm{P}(\sim c \mid a)$. Generally, a probabilistic modus ponens inference depends only on $\mathrm{P}(\sim c \mid a)$, while probabilized modus tollens, DA and $\mathrm{AC}$ inferences additionally depend on $\mathrm{P}(a)$ and $\mathrm{P}(c)$. See Oaksford and Chater (2008; 2009).

${ }^{18}$ (6) says that $\sim a$ is negatively relevant to $c$ because $\sim a$ makes $\sim c$ more probable than it was initially.

${ }^{19}$ Assume for the sake of argument that the proponent assigns $0.5<\mathrm{P}_{\mathrm{i}}(a)<1$, so that $a$ is more probable than not, and that she moreover chooses the likelihood, $\mathrm{P}_{\mathrm{i}}(a \mid c)$, such that $\mathrm{P}_{\mathrm{i}}(c \mid a)$ is rendered sufficiently high for her purpose (e.g., beyond some threshold, $t$; see below). But now assume further that she remains uncommitted to the exact value of $\mathrm{P}_{\mathrm{i}}(c)$. Therefore, $\mathrm{P}_{\mathrm{i}}(c)$ can range over all values that satisfy $\mathrm{P}_{\mathrm{i}}(c \mid a)>\mathrm{P}_{\mathrm{i}}(c)$ given her likelihood, $\mathrm{P}_{\mathrm{i}}(a \mid c)$. In a probabilized dialectical scenario analogous to Stone's case, assume finally that the proponent responds to the opponent's objection by adopting the opponent's claim that $0.5<\mathrm{P}_{\mathrm{i}}(\sim a)<1$. To evaluate the consequences of this move, one now needs to conditionalize on $\mathrm{P}_{\mathrm{i}}(\sim a)$ in order to find $\mathrm{P}_{\mathrm{i}}(\sim c \mid \sim a)$. Because of the proponent's loose stance on $\mathrm{P}_{\mathrm{i}}(c)$ before hearing the opponent's objection, however, that $\mathrm{P}_{\mathrm{i}}(a)>0.5$ and that $\mathrm{P}_{\mathrm{i}}(c \mid a)$ was deemed sufficiently high simply does not entail a definite value for $\mathrm{P}_{\mathrm{i}}(\sim a \mid \sim c)$, nor of course some such value that - upon conditionalization on $\sim a$-also leaves $\mathrm{P}_{\mathrm{i}}(\sim c \mid \sim a)$ sufficiently

(C) David Godden and Frank Zenker. Informal Logic, Vol. 35, No. 1 (2015), pp. 88-134. 


\section{David Godden and Frank Zenker}

about probabilistic support relations between antecedents and consequents come what may. Therefore, particularly Stone's desired conclusion - that $\sim c$ is sufficiently probable given $\sim a-$ won't follow from each and every gung-ho assignment of probability values even if $0<\mathrm{P}(\phi)=1-\mathrm{P}(\sim \phi)<1 .{ }^{20}$ Moreover, if - as per Stone's example $-\mathrm{P}_{\mathrm{i}}(a)$ and $\mathrm{P}_{\mathrm{i}}(\sim a)$ are assigned the values zero or one, then premise subtraction remains ill-defined in the context of Bayes' theorem. After all, when $\mathrm{P}(a)=1$, then $a$ is treated as indubitable, upon which the theorem ceases to offer guidance for the subtraction of $a$. In fact, subtraction of something that qualifies as being beyond doubt is widely treated as an arational move in this context, that is, a move on which BT provides no rational guidance one way or another.

Rather than employ BT in order to address premise subtraction, one can turn to Jeffrey conditionalization (JC):

$$
\text { (JC) } \mathrm{P}_{\mathrm{f}}(c)=\mathrm{P}_{\mathrm{i}}(c \mid a) \mathrm{P}_{\mathrm{f}}(a)+\mathrm{P}_{\mathrm{i}}(c \mid \sim a) \mathrm{P}_{\mathrm{f}}(\sim a)^{21}
$$

In Stone's case, when the proponent claims that $a$ makes $c$ more probable she can be taken to be committed to $\mathrm{P}_{\mathrm{f}}(c)>t \geq \mathrm{P}_{\mathrm{i}}(c)$, where $t$ is a threshold given by a probability value arbitrarily smaller than $\mathrm{P}_{\mathrm{f}}(c)$ and at least as large as $\mathrm{P}_{\mathrm{i}}(c)$. Further, if $\mathrm{P}_{\mathrm{f}}(a)=1$ and so $\mathrm{P}_{\mathrm{f}}(\sim a)=0$, i.e., $a$ is true, then $\mathrm{JC}$ reduces to its left hand summand:

low. But this value is needed to solve the corresponding instance of Bayes' theorem, namely: $\mathrm{P}_{\mathrm{f}}(\sim c \mid \sim a)=\left[\mathrm{P}_{\mathrm{i}}(\sim a \mid \sim c) \mathrm{P}_{\mathrm{i}}(\sim c)\right] / \mathrm{P}_{\mathrm{i}}(\sim a)$. See Sober (2002). Our efforts below are oriented towards supplying information that renders the opponent's claim that $\mathrm{P}_{\mathrm{f}}(\sim c \mid \sim a)>\mathrm{P}_{\mathrm{f}}(c \mid \sim a)$ acceptable. Extending this footnote, Zenker (2015) provides a dialectical treatment which relies on material in this section.

${ }^{20}$ It is beyond the scope of this article to provide an analytical characterization of the bounds that arise when $0.5<\mathrm{P}(c \mid a), \mathrm{P}(\sim c \mid \sim a)<1$, so that both $\mathrm{P}(c \mid a)$ and $\mathrm{P}(\sim c \mid \sim a)$ count as probabilistically supported or probabilistically confirmed if $0.5<\mathrm{P}(a), \mathrm{P}(\sim a)<1$. See Oaksford and Chater (2008; 2009), Sober (2002), and Wagner (2004) for related work.

${ }^{21}$ The posterior probability of the conclusion, $\mathrm{P}_{\mathrm{f}}(c)$, here depends on the posterior probability of the antecedent, $\mathrm{P}_{\mathrm{f}}(a)=1-\mathrm{P}_{\mathrm{f}}(\sim a)$, as well as on the prior probabilities $\mathrm{P}_{\mathrm{i}}(c \mid a)$ and $\mathrm{P}_{\mathrm{i}}(c \mid \sim a)$. Jeffrey conditionalization generalizes the Bayesian theorem; BT corresponds to the limiting case where one summand of JC is set to 1 . To verify, recall that $\mathrm{P}_{\mathrm{f}}(c)=\mathrm{P}_{\mathrm{i}}(c \mid a)$. Since $\mathrm{P}(a \& c)=\mathrm{P}(c \& a)=\mathrm{P}(a \mid c) \mathrm{P}(c)=\mathrm{P}(c \mid a) \mathrm{P}(a)$, by substitution, if $\mathrm{P}_{\mathrm{f}}(a)=1$, then the expression $\mathrm{P}_{\mathrm{f}}(c)=\mathrm{P}_{\mathrm{i}}(c \mid a) P_{\mathrm{f}}(a)+\mathrm{P}_{\mathrm{i}}(c \mid \sim a) \mathrm{P}_{\mathrm{f}}(\sim a)$ reduces to $\mathrm{P}_{\mathrm{f}}(c)=\mathrm{P}_{\mathrm{f}}(a \& c)$, and so $\mathrm{P}_{\mathrm{f}}(c \mid a)=\mathrm{P}(a \mid c) \mathrm{P}(c) / \mathrm{P}(a)$ becomes $\mathrm{P}_{\mathrm{f}}(c \mid a)=\mathrm{P}_{\mathrm{f}}(a \& c)$. The case is analogous when $\mathrm{P}_{\mathrm{f}}(\sim a)=1$.

(C) David Godden and Frank Zenker. Informal Logic, Vol. 35, No. 1 (2015), pp. 88-134. 
(7) $\mathrm{P}_{\mathrm{f}}(c)=\mathrm{P}_{\mathrm{i}}(c \mid a) \mathrm{P}_{\mathrm{f}}(a)>t$

As an assumption of relevance (AR) that will be crucial for Stone's argument, we take the proponent's initial claim - that $a$ raises the probability of $c$ to a value above some threshold $t$ - to entail the following:

(AR) If also $\sim a$ raised the probability of $c$, then it does so at most to $t$, so that $\mathrm{P}_{\mathrm{i}}(c \mid \sim a) \leq t$.

If, as per Stone's case, $a$ is now subtracted because $a$ is false, i.e., if $\mathrm{P}_{\mathrm{f}}(\sim a)=1$ and so $\mathrm{P}_{\mathrm{f}}(a)=0$, then - analogously to (7)- $\mathrm{JC}$ reduces to its right hand summand:

(8) $\mathrm{P}_{\mathrm{f}}(c)=\mathrm{P}_{\mathrm{i}}(c \mid \sim a) \mathrm{P}_{\mathrm{f}}(\sim a) \leq t$

Because $\mathrm{P}_{\mathrm{i}}(c \mid \sim a)=1-\mathrm{P}_{\mathrm{i}}(\sim c \mid \sim a)$, it follows for the standard threshold of probabilistic support $t=0.5$ that upon retracting $a$, i.e., $\mathrm{P}_{\mathrm{f}}(\sim a)=1$, the value of $\mathrm{P}_{\mathrm{f}}(c)$ falls below $t$ only if $\mathrm{P}_{\mathrm{i}}(\sim c \mid \sim a)>t$. (To assume that $\mathrm{P}_{\mathrm{i}}(\sim c \mid \sim a)>t$ for $t=0.5$ amounts to a probabilized version of the conditional perfection strategy, discussed in Sect. 3, because the assumption renders the conditional convertible, probabilistically speaking). The cogency of Stone's total evidence argument, therefore, depends not only on the initial assumption $\mathrm{P}_{\mathrm{f}}(c)>\mathrm{P}_{\mathrm{i}}(c)$, as stated in (5), but additionally depends on (AR) - i.e., $\mathrm{P}_{\mathrm{i}}(c \mid \sim a) \leq t$ for $t=0.5$-which effectively states Stone's desired conclusion. After all, once $\mathrm{P}_{\mathrm{i}}(c \mid \sim a)$ falls to or below the value 0.5 , then $c$ no longer receives sufficient probabilistic support in the event that $\sim a$, since - analogously to (8)we have it that $\mathrm{P}_{\mathrm{f}}(\sim c)=\mathrm{P}_{\mathrm{i}}(\sim c \mid \sim a) \mathrm{P}(\sim a)$, and so if $\mathrm{P}(\sim a)=1$, then $\mathrm{P}_{\mathrm{f}}(\sim c)=\mathrm{P}_{\mathrm{i}}(\sim c \mid \sim a)$.

Hence, rather than $\mathrm{P}_{\mathrm{f}}(c)=\mathrm{P}_{\mathrm{i}}(c \mid a)>\mathrm{P}_{\mathrm{i}}(c)$, as in (7), the proponent would have had to be committed to:

(9) $\mathrm{P}_{\mathrm{f}}(c)=\mathrm{P}_{\mathrm{i}}(c \mid a)>t>\mathrm{P}_{\mathrm{i}}(c)$ and $\mathrm{P}_{\mathrm{i}}(c \mid \sim a) \leq t$, for $t=0.5$

for the opponent to establish probabilistic support for $\sim c$ by subtracting $a$. That much, of course, may have been intuitively clear all along. The point of the exercise was to trace the assumption that remained implicit, extrinsic to, and holding (or not) independently of the overt DA argument. 


\subsection{Total evidence and the cogency of $D A$}

We have so far argued that even in cases where $a$ supports $c$ by making $c$ more probable than it was initially - the subtraction of $a$, i.e., the acceptance of $\sim a$, only supports $\sim c$ provided a specific relation holds between prior probabilities and the standard threshold of probabilistic support, 0.5. Thus, the total evidence argument does not hold without further qualification. But might the total evidence argument perhaps hold in cases where a probabilized version of modus ponens is cogent? After all, if $\mathrm{P}_{\mathrm{f}}(c)=\mathrm{P}_{\mathrm{f}}(c \mid a)>0.5>\mathrm{P}_{\mathrm{i}}(c)$, then $\quad \mathrm{P}_{\mathrm{f}}(c \mid a)>\mathrm{P}_{\mathrm{f}}(\sim c \mid a)$, since $\mathrm{P}_{\mathrm{f}}(c \mid a)=1-\mathrm{P}_{\mathrm{f}}(\sim c \mid a)$. So is DA a cogent form of inference in such circumstances? According to Stone, it would seem so. Recall his claim (p. 350, notation adapted) that:

Where $c$ is a claim which has been supported by some reasons, the force of denying the antecedent is not only that we should not accept the conclusion $c$ for the reasons given in the initial argument, but that we should probably accept not $c$.

Accordingly, Stone would thus be committed not only to the view that denied antecedents offer support to negated consequents - i.e., to (6) - but also to the stronger claim that, because of this, DA is a cogent probabilistic form of inference. We now proceed to show that this claim is also in need of qualification.

For DA to be a cogent opponent-move, as we have seen, the proponent must be committed to (9). That is, the reasons, $a$, must provide sufficient probabilistic support for the conclusion, $c$. This requires first that, in case $\mathrm{P}(a)=1, a$ make $c$ more probable than its complement, $\sim c$. And second it requires that, if $\mathrm{P}(\sim a)=1$, then $\sim a$ make $\sim c$ more probable that its complement, $c$. Both conditions can be stated as follows:

$$
\begin{aligned}
& \mathrm{P}_{\mathrm{f}}(c)=\mathrm{P}_{\mathrm{i}}(c \mid a)>0.5>\mathrm{P}_{\mathrm{i}}(\sim c \mid a) \text { and } \\
& \mathrm{P}_{\mathrm{f}}(\sim c)=\mathrm{P}_{\mathrm{i}}(\sim c \mid \sim a)>0.5>\mathrm{P}_{\mathrm{i}}(c \mid \sim a)
\end{aligned}
$$

Now, (10) is not a consequence of Stone's total evidence thesis, as stated in (6), let alone a consequence of (5). Rather, (10) depends on the case and so is always contingent relative to what has been claimed so far. Consider a standard 6/49 lottery where 6 numbers on a ticket must exactly match 6 numbers randomly drawn out of 49 , irrespective of order. The following conditional is true:

(C) David Godden and Frank Zenker. Informal Logic, Vol. 35, No. 1 (2015), pp. 88-134. 
(11) If the first number on your ticket doesn't match (a), then it isn't a winning ticket $(c)$.

Here, modus ponens and modus tollens are cogent, indeed sound, inferences. But denying the antecedent, i.e., setting $\mathrm{P}(\sim a)=1$, is clearly abysmal. While the odds of winning this lottery improve seven-fold provided the first number matches, they nevertheless remain at nearly two million to one against. So the second conjunct in (10) is false because in this case: $\mathrm{P}_{\mathrm{f}}(\sim c \mid \sim a)<0.5<\mathrm{P}_{\mathrm{f}}(c \mid \sim a)$. Similar things hold for $\mathrm{AC}$, i.e., when setting $\mathrm{P}(c)=1$. The odds of matching the first number are roughly 1 in 6.74 ; fewer than $13 \%$ of nearly 14 million losing tickets will have matched the first number, so $\mathrm{P}_{\mathrm{f}}(\sim a \mid c)<0.5<\mathrm{P}_{\mathrm{f}}(a \mid c){ }^{22}$

Such cases occur when the antecedent states a uniquely satisfied, genuinely sufficient condition for the consequent which, by contrast, is widely and variously satisfied. For example:

(12) If someone is the president of the United States, then they are born an American citizen.

Given the size of the US population, the effect of an unsatisfied sufficient condition or a satisfied necessary condition on our total evidence is practically negligible. Hence, even in cases where the total evidence principle holds - i.e., where $\sim a$ is positively relevant to $\sim c$ - DA fails to be a cogent form of inference unless further conditions are met that reflect suitable probability distributions.

\section{The greener approach to logic?}

Before concluding, we briefly return to Bayes' theorem (BT) and address a contribution by Floridi (2009) that is invoked by Stone's second argument. Recall BT* (see Sect. 5.3):

${ }^{22}$ As already noted, probabilistic versions of conditional arguments generally depend on features not stated in their premises. Particularly modus ponens (MP) depends only on $\mathrm{P}(\sim c \mid a)$, while modus tollens (MT), DA and AC additionally depend on the distribution of the prior probabilities $\mathrm{P}(a)$ and $\mathrm{P}(c)$ (Oaksford and Chater, 2008; 2009). Hahn and Oaksford (2012, pp. 286 ff.) describe the distribution of priors that make DA inferentially stronger than MP.

(C) David Godden and Frank Zenker. Informal Logic, Vol. 35, No. 1 (2015), pp. 88-134. 


$$
\mathrm{P}(c \mid a)=\mathrm{P}(a \mid c) \mathrm{P}(c) /[\mathrm{P}(a \mid c) \mathrm{P}(c)+\mathrm{P}(a \mid \sim c) \mathrm{P}(\sim c)]
$$

When $\mathrm{P}(a \mid \sim c)=0$, then the denominator,

$$
\mathrm{P}(a \mid c) \mathrm{P}(c)+\mathrm{P}(a \mid \sim c) \mathrm{P}(\sim c)
$$

reduces to $\mathrm{P}(a \mid c) \mathrm{P}(c)$, since $\mathrm{P}(a \mid \sim c) \mathrm{P}(\sim c)=0$. Now being identical to the numerator, $\mathrm{P}(c \mid a)=1 / 1=1$. So if $\mathrm{P}(a \mid \sim c)=0$, then $\mathrm{P}(c \mid a)=1$. Hence, "Bayes theorem is degraded to a double implication: $a \leftrightarrow c, c \mid-a$ " (Floridi, 2009, p. 399, notation adapted), which is a deductively valid inference. Moreover, it can easily be verified that "if there are some false positives, that is, if $\mathrm{P}(a \mid \sim c)>0$, then $\mathrm{P}(c \mid a)<1$ and the formula bears a strong family resemblance to the AC fallacy: $a \rightarrow c, c \mid-a$ " (ibid.). ${ }^{23}$ The case for DA is analogous. So Floridi can call both AC and DA "Bayes' theorem stripped of some of its probabilities" (p. 400).

DA and $\mathrm{AC}$... assume (and here is the logical mistake) that there are no false positives (double implication), or that, if there are, they are so improbable as to be disregardable (degraded Bayes' theorem). So DA and AC are Bayesian "quick and dirty" informational shortcuts. (2009, p. 400)

We can only agree and add a reminder: if $\mathrm{P}(a \mid \sim c)=0$, then we have left the realm of probabilities and can reason by classical logic. The term 'Bayesian' is at this point perhaps a mere gesture. The cogency of DA and AC when $\mathrm{P}(a \mid \sim c)>0$, however, still depends on the distance of $\mathrm{P}(a \mid \sim c)$ from 0 . That distance indicates how large a bet we make when we ignore the probabilities, whatever they are. But how small a difference might leave DA or AC cogent forms of argumentation thus comes to depend also on factors such as the stake size (i.e., the cost of getting things wrong) and one's adversity to losses (Kahneman and Tversky, 1979; Blamey, 2013). What Floridi has (nicely) called a "greener approach to logic," then, remains a trade-off between getting the probabilities right for some purpose and getting to a conclusion with a minimum of cognitive effort for some other purpose.

Stone (2012, esp. p. 341) correctly presents the basics of Floridi's argument. But he appears to slide between two incom-

\footnotetext{
${ }^{23}$ If $\mathrm{P}(a \mid \sim c)>0$, then the summand of $\mathrm{BT}^{*}$ 's denominator, $\mathrm{P}(a \mid c) \mathrm{P}(c)+\mathrm{P}(a \mid \sim c) \mathrm{P}(\sim c)$, will be non-zero. The denominator now exceeds the numerator, $\mathrm{P}(a \mid c) \mathrm{P}(c)$, and so $\mathrm{P}(c \mid a)<0$.
} 
patible commitments, viz., that the false positive rate is a relevant magnitude and that it is not. This leads Stone to slightly overstate his conclusions, which he bases on the following example of a DA argument:

If Carl embezzled the college funds, then he is guilty of a felony $[\mathrm{P}(c \mid a)=1]$.

Carl did not embezzle the college funds $[\mathrm{P}(\sim a)=1]$.

Therefore: Carl is not guilty of a felony $[\mathrm{P}(\sim c)=1]$.

(Copi and Cohen, 2009, p. 300, notation adapted)

Stone states:

For the opponent to respond to our [DA] argument ... by providing counter arguments that Carl might be selling drugs in the next county or that he might be guilty of a felony $\mathrm{DUI}^{24}$ [i.e., pointing to the uncertainty of $\mathrm{P}(c \mid \sim a)$ ] is easy but irrelevant. If the [DA] argument ... includes reliable evidence that Carl did not embezzle the funds [i.e., $\mathrm{P}(\sim a)=1$ ], then the argument goes to establish that Carl is not guilty of a felony in light of the limited probability that Carl is guilty of some other felony. ${ }^{25}$ So the Bayesian analysis supports the view that denying the antecedent can be an effective inductive argument strategy, especially in response to another argument. (Stone, 2012, p. 341; italics added)

As we have seen, $\mathrm{P}(\sim c \mid \sim a)=1-\mathrm{P}(c \mid \sim a)$. Therefore, the probability that Carl is not guilty of a felony given that he did not embezzle the college funds, $\mathrm{P}(\sim c \mid \sim a)$, depends directly on the probability of Carl being guilty of some other felony, $\mathrm{P}(c \mid \sim a)$. So $\mathrm{P}(c \mid \sim a)$ being "limited," i.e., taking a very low value, is a crucial assumption. Whether being invoked in response to another argument or not, it better be true. Discourse participants may of course be aware, or may easily come to know or believe, that $\mathrm{P}(c \mid \sim a)$ is very low in some context. For purposes at hand, they can therefore leave that condition implicit. But the cogency of DA arguments depends on it just the same.

${ }^{24}$ DUI stands for 'driving under the influence' of alcohol, which in some US states may be treated as a felony rather than a misdemeanor, for instance in the repeated case.

${ }^{25}$ Stone's conclusion could be expressed as $\mathrm{P}(\sim c \mid \sim a \& h)$, where $h$ is some plausible function of $\mathrm{P}(c \mid \sim a)$ that might otherwise be referred to as hope or trust. 
Floridi (2009) had argued for the cogency of DA and AC largely on grounds of cognitive and epistemic ecology, a.k.a. our bounded rationality (Simon, 1956).

[L]ogic has been guilty of an 'ungreen policy,' by considering some formal logic fallacies as absolutely worthless rubbish, only fit for the conceptual junkyard ... $[\mathrm{T}]$ here is a greener and much more reasonable interpretation of such fallacies, which shows that they can be rather useful, if quick and dirty, and probably riskier, ways to gain and manage one's information. Some logical fallacies are not mere mistakes of no value but informational shortcuts that can be epistemically fruitful if carefully managed. (p. 318 , italics added)

Although they are fallible, quick, and dirty, DA and AC are here presented as effective heuristics. When well-managed, or so is the claim, they can be suited to our epistemic environments given our cognitive resources and goals. Their cogency, however, as Floridi also points out, depends on several conditions. He mentions the soundness of $a \rightarrow c$, a relevant connection between $a$ and $c$, and further constraints such as the mutual exclusivity and exhaustiveness of $a$-events over the sample space, and a non-zero probability of $c$-events (Floridi 2009, p. 323). While it may thus seem that little management is required, such assumptions are in fact substantial. As we have shown in detail, these assumptions should be checked carefully if things of great (practical) importance depend on them.

\section{Conclusion}

\subsection{Recap}

Having surveyed extant treatments of DA and AC (Sect. 3), we made a preliminary, presumptive case that on any prevailing interpretation of indicative conditionals (reviewed in Sect. 2) DA and $\mathrm{AC}$ arguments are incogent (Sect. 4). Rather, in whatever way indicative conditionals are interpreted, the cogency of DA and $\mathrm{AC}$ depends on contingent factors that are unasserted by, and remain independent of, the denial of antecedents or the affirmation of consequents. The unstated conditions needed to grant probative force to $\mathrm{DA}$ and $\mathrm{AC}$ can be summarized as follows: 
(i) on defeasible and probabilistic interpretations: probability distributions concerning the coincidence (or covariation) of antecedent with consequent conditions, and the coincidence (or covariation) of complement conditions;

(ii) on Stalnaker interpretations: the relative proximity of relevant possible worlds to the actual one;

(iii) on interpretations as valid but enthymematic arguments: the unstated, converse conditional;

(iv) in contexts of pragmatic justification: the applicability of the relevant scale of implicature to license conditional perfection.

That the cogency of DA and AC arguments depends on such extraneous and unstated conditions challenges recent attempts to rehabilitate them as cogent patterns of argument (Sects. 5, 6). This scholarship presents DA and AC reasoning as generally probative, if not cogent: Stone (2012) on the grounds that DA and $\mathrm{AC}$ are licensed by the principle of total evidence, and Floridi (2009) on the grounds that DA and AC can be efficient and effective applications of Bayesian probability- "informational shortcuts that can be epistemically fruitful if carefully managed" (2009, p. 318). Yet, neither argument fully succeeds in establishing the good inferential name of denying antecedents and affirming consequents come what may, since, for all accounts we have considered, the premises stated in DA and AC arguments fail to be probative unless they are taken in conjunction with additional, unstated, contingent assumptions.

\subsection{Enthymemes and managing inferential risk}

The case against the cogency of DA and AC might, as one reviewer commented, be seen as little more than the accusation that DA and AC are enthymematic arguments that are entirely cogent when properly reconstructed with some suitable and appropriate condition(s). Since enthymemes are both typical of ordinary argumentation and are widely viewed as being acceptable even though they rely on unstated assumptions, why should DA and AC not be granted the same courtesy? Moreover, as the reviewer went on to claim, empirical evidence suggests that, "with respect to various (alleged) fallacies, people are actually well-attuned to unstated factors affecting their cogency (or lack thereof)." For example, empirical evidence suggests that we monitor unstated cogency conditions for arguments ad hominem (Harris et al, 2012), ad ignorantiam, petitio principii, and slippery slope (Hahn and Oaksford, 2007). If something similar

(C) David Godden and Frank Zenker. Informal Logic, Vol. 35, No. 1 (2015), pp. $88-134$. 
were typical of ordinary uses of DA and AC arguments, then our claims of their default incogency would be significantly undermined.

Notice that neither Stone nor Floridi rely on empirical data to the effect that we use, or accept, DA or AC arguments infrequently, or that we sensitively attend to any of the above conditions when doing so; nor do they argue that DA and AC arguments should be interpreted enthymematically. Rather, Stone (2012) argues that DA arguments are probative, and can be cogent - not enthymematically, but as stated, that is, without the addition of any unstated premises. Similarly, Floridi (2009, pp. $321 \mathrm{ff}$.) argues that it is efficient and effective, if not rational, to take informational shortcuts like DA and AC in ordinary life, and to disregard probabilities such as base rates or false positive rates, in order extract useful information from our environments in a "quick and dirty" way. While Floridi concedes that these cognitive shortcuts are argumentatively disastrous and mathematically calamitous, they are nevertheless presented as powerful inferential tools - fairly accurate reasoning shortcuts that get things right most of the time, such that we are right to generally rely upon them (2009, pp. 324, 322). Here, it is not clear whether Floridi is most charitably read as saying that we are right to ignore ("disregard") certain probabilities, or that we are right to assume that the odds will favor our conclusions.

Responding now to a reviewer's comments, let us clarify a couple of points. First, we do not claim that the incogency of $\mathrm{DA}$ and $\mathrm{AC}$ arguments results from that something has been left unstated; rather the problem we identify concerns what has been left unstated. We do not intend to prohibit the use of enthymematic argument or inference, of course. For example, we fully endorse Moldovan's (2009, pp. 318ff.) analysis according to which, first, whenever conditional perfection is pragmatically justified by scalar conversational implicature, then inferences that apparently deny the antecedent or affirm the consequent will be valid, albeit enthymematic, cases of modus tollens or modus ponens; and, second, supplementing the stated argument with the converse conditional (thereby attributing commitment to it to the arguer) is warranted by pragmatic considerations that form part of the conversational exchange-something the arguer would be aware of - so that attributing commitment to the converse conditional would be justified.

Moreover, ordinary inferences and arguments rely on common and tacit background knowledge or shared belief. It is an ancient insight that arguers can regularly leave information unsaid which they may expect their audience to readily "fill in."

(C) David Godden and Frank Zenker. Informal Logic, Vol. 35, No. 1 (2015), pp. $88-134$. 
"Socrates is a man, therefore he is mortal" provides a classical example (see Rapp, 2010). (On Hitchcock's (1998) ethymematic consequence relation, by contrast, no such information would even be missing, while the conclusion can still follow definitely, if never logically.) More generally, the practicality of communication requires that more be left unstated than what is actually stated, for any communicative exchange. As Fogelin (1985, p. 3) puts it:

An important feature of these shared beliefs and preferences is that they lie in the background, unmentioned. They guide the discussion, but they are not themselves the subject of it. ... They provide the framework or the structure within which reasons can be marshalled, where marshalling reasons is typically a matter of citing facts in a way that their significance becomes clear.

Thus, this background of shared agreement doesn't merely fill in the gaps of elliptical reasoning; rather, it makes reason-givingindeed communicative understanding - possible.

Yet, these features mark important differences between the unstated background of agreement in ordinary enthymematic argument, and what DA and AC arguments leave unstated. As we saw, DA and AC arguments fail to assert the conditions on which the truth of their conclusions, and indeed the positive relevance of their stated premises, depend. These are properly construed as reasons, not background assumptions. Premises that are unproblematically supplemented to putatively enthymematic arguments are, minimally, ones that are reasonably acceptable to both arguer and audience, and also accepted by both arguer and audience. Only then can one take it for granted that these premises are not at issue - that they go without saying. Yet, with DA and AC arguments this does not seem to hold. The unstated conditions listed above, on which the cogency of DA and AC arguments depend, do not ordinarily go without saying. Just as we cannot generally presume them to be true, we cannot generally presume them to be reasonably acceptable to, or accepted by, arguer and audience. Indeed, because they give the very conditions on which the cogency of the given argument depends, they are precisely the kinds of claims that are, or should be, at issue, and should therefore be expected to be found among the stated premises of the argument. Finally, Section 3.1 reviews the several problems, both interpretative and evaluative, that affect attempts to supplement DA and AC arguments with unstat- 
ed premises that are not obviously among the shared beliefs of the arguers.

This brings us to the reviewer's second comment, according to which we should presume that the unstated cogency conditions are in fact acceptable to, and reasonably accepted by, arguers and audiences on the evidence of experimental participants who seem to reliably monitor such conditions. Indeed, some empirical studies do show that participants' evaluations of particular DA and AC arguments, among them some that were enthymematic in the classical sense, map closely onto what a Bayesian model singles out as the rational response (Oaksford, Chater and Larkin, 2000). For instance, data by Ellis (1991), reported in Evans, Newstead and Byrne (1993), is consistent with the interpretation that the most frequent employment of DA and AC arguments in the tested contexts occurs when speakers communicate promises, threats, and conditional intentions. As Perkins (2002, p. 208) notes, "this accords well with a practical view of people's treatment of conditionals: Why declare a promise, threat or intention unless you do not mean to follow through should the condition fail?" For instance, "If you are nice, I will buy you candy" (promise); "If you leave the salad, you won't get dessert!" (threat); "If the money arrives tomorrow, we'll go to a restaurant" (conditional intention). Such apparently DA and AC structures are presumptively cogent; while they depend on unstated factors all the same, ordinary speakers seem to get the relevant unstated probabilities right.

In response, notice that these cases can readily be interpreted as being instances of conditional perfection by scalar conversational implicature; so understood, they are examples of presumptively cogent inferences. But the question remains whether subjects track pragmatic conversational cues (i.e., abide by Gricean conversational norms, and expect their interlocutors to do the same), or whether they track information that is extraneous to the conversational exchange such as base rate or false positive rate.

More generally, one cannot simply assume by fiat that arguers sensitively track the unstated cogency conditions on which DA and AC inferences depend. The empirical evidence purporting to show that arguers do so is, in our view, equivocal and inconclusive. Moreover, other empirical evidence suggests that arguers instead (or perhaps also) attend to various irrelevant aspects of reasoning problems, while neglecting relevant aspects. For example, studies of two-premise conditional reasoning show that reasoners respond to logically irrelevant aspects such as premise order (Girotto, Mazzocco and Tasso, 1997) and to 
whether antecedent or consequent conditions are negated (Evans and Lynch, 1973), resulting in the matching bias (Evans, 1998). Yet other studies show that reasoners fail to attend to logically relevant information. For example, one of the first cognitive biases to be named, the confirmation bias (Wason, 1966), regularly registers as being alive and well (Nickerson, 1998; Mendela et al, 2011). Similarly, base-rate neglect (Eddy, 1982) (which can be mitigated, though not eliminated, by presenting relevant information in a frequentist format (Gigerenzer and Hoffrage, 1995)) remains prevalent and recalcitrant (Barbey and Sloman, 2007).

Overall, we agree with Floridi that DA and AC can be likened to heuristics: they can be reliable in some limited domains of application but become sources of error when applied outside of those domains. What is the (most) prudent policy of use in this situation? Floridi advises a permissive usage policy, with the caveat that the use of such heuristics must be properly managed. We agree with Floridi that DA and AC must be properly managed if they are to be used rationally and responsibly, and would emphasize this aspect more. After all, it is easy to focus on contexts where the cost of error is small. In other ordinary situations, however, the consequences may amount to decisions between life and death. For instance, the role of cognitive errors, including biases and the improper application of heuristics, in medical misdiagnoses is well documented (Croskerry, 2003; Elstein, 1999; Graber, 2005; Mendela et al, 2011; Normal and Eva, 2010; Pines, 2006). Further, while debiasing is a uniquely difficult task (Kenyon, 2014; Willingham, 2011), at least some progress is being made, particularly in fields like medicine where the stakes are highest. Interestingly for our present purposes, Croskerry (2003) finds that a principal element of effective debiasing is "metacognition, a reflective approach to problem solving that involves stepping back from the immediate problem to examine and reflect on the thinking process" ( $p$. 775). Yet, this aspect of cognitive management is underemphasized by the "shoot-first-and-ask-questions-later" advocate of heuristics (cf. Floridi, 2009, p. 324). More recent work by Croskerry, Singhal and Mamede (2013a, b) concludes that "All [effective debiasing techniques studied] share a common feature that involves a deliberate decoupling from Type 1 intuitive processing and moving to Type 2 analytical processing so that eventually unexamined intuitive judgments can be submitted to verification. This decoupling step appears to be the critical feature of cognitive and affective debiasing" (2013a, p. ii58). 
A cognitively responsible employment of heuristics would not carelessly deploy them outside the domains where they are known to reliably apply. Thus, the proper management of our logical policies involves more than the psychologistic recycling of our cognitive habits and inclinations as norms by documenting our cognitive proclivities in domains where they succeed and ignoring those where they don't. Rationality, so conceived, is not only irresponsible but unsustainable. Adopting a greener view of rationality presupposes that one is already convinced of our cognitive reliability, and has access to recognizably good starting points for our inferences. But this concedes a standard of correctness and inferential goodness that remains external to our own psychological states and processes. Having examined some of these external standards, whatever probative merits DA and $\mathrm{AC}$ have on some occasion of use were traced back to factors not invoked by the DA or AC inferences themselves. Therefore our prescriptive position is that, if $\mathrm{DA}$ and $\mathrm{AC}$ are to be used reliably and responsibility, then users should be cognizant of these unstated assumptions and should evaluate them as part of the argument, because these assumptions contribute ineliminably to the argument's cogency.

\subsection{Lack of cogency and fallaciousness}

How far does all of this go towards establishing that DA and AC are, or remain, fallacies? Traditionally, fallacies are recognizable patterns of reasoning that we commonly but mistakenly take to be cogent. ${ }^{26}$ It is well documented that people tend to offer

\footnotetext{
${ }^{26}$ Contemporary work beginning with Hamblin (1970) does much to amend and augment classical definitions and classification schemes, while retaining some notion that bears a family resemblance to this basic idea. For example, the Woods/Walton account (see, e.g., Woods \& Walton, 2007) treats fallacies as defeasible patterns of reasoning that can go wrong when improperly used (e.g., in inappropriate contexts). From this, Walton (1995, pp. 17ff.) developed a pragmatic account of fallacy according to which:

\begin{abstract}
fallacies are first and foremost identified as being certain distinctive types of arguments, as indicated by being instances of their characteristic argumentation schemes. ... Then the fallacy is analyzed as a certain type of misuse of the argumentation scheme. ... According to the new theory, a fallacy is (first and foremost) an argumentation scheme used wrongly.
\end{abstract}

Similarly, van Eemeren and Grootendorst (2004, p. 162; cf. p. 22, ch.7) consider any violation of the rules of a critical discussion in at least one of the

(C) David Godden and Frank Zenker. Informal Logic, Vol. 35, No. 1 (2015), pp. 88-134. 
reasons in ways that prima facie instantiate DA and AC patterns of inference (Evans and Over, 2004, chs. 3, 4). It used to be the case that this, combined with the stereotypicality and formal invalidity of DA and AC, was deemed sufficient to classify DA and $\mathrm{AC}$ as formal fallacies. But deductive validity provides an inordinately high standard for the cogency of ordinary day-today reasoning, and hence yields a rather low threshold for fallaciousness.

It is widely recognized, moreover, that our ordinary reasoning tasks require neither certainty nor entailment; our tolerance for risks in reasoning thus makes deduction an unfit standard for the evaluation of such reasoning. But can our tolerance for inferential risk, together with the fact that DA and $\mathrm{AC}$ can have instances where their premises and conclusions are true, suffice to rehabilitate them as presumptively cogent inductive inferences? We argue that it cannot.

Firstly, invalid arguments are not forms that entirely lack truth-preserving instances. Rather, they are forms whose validity cannot be fully relied upon because they have at least one invalid instance. Similarly, fallacies are not forms (or schemata) that have no cogent applications. Rather, they are forms whose cogency cannot be fully relied upon either-ones where cogency in any instance depends on factors not stated in the argument itself. Therefore, the erroneousness of fallacies does not require that they always lead to error or always fail to provide adequate reason. Rather, the relevant reason for their erroneousness is that fallacies are unreliably cogent inferences - they do not reliably cite as reasons the grounds on which the truth or acceptability of their conclusions depend. DA and AC are fallacious in exactly this sense.

Secondly, we have established the incogency of DA and $\mathrm{AC}$ arguments on any prevailing account of indicative conditionals and despite the recent arguments of Stone (2012) and Floridi (2009). Stone and Floridi have each claimed to show that DA and AC are not fallacious - not on the grounds that they are infrequent or lack a recognizable pattern, but because they can

four discussion stages to obstruct or impede the resolution of a critical discussion, and so to amount to a fallacy.

Here we use the term 'fallacy' in a theoretically neutral way, aiming at that pre-theoretical sense of fallacy that all theories of fallacy hope to account for. Generally speaking, we take fallacies to be stereotypical errors of reasoning that are commonly and mistakenly accepted as cogent. Crucially, such errors needn't be logical, e.g., begging the question and equivocation are not logical faults.

(C) David Godden and Frank Zenker. Informal Logic, Vol. 35, No. 1 (2015), pp. 88-134. 
be correct, cogent forms of reasoning, generally speaking. We have shown that, without suitable qualification, such claims are problematic.

We have further identified the source of the erroneousness of DA and AC reasoning. The erroneousness of DA and AC is not explained by the frequency of counter-examples (i.e., instances where true premises lead to false conclusions), but rather by the fact that the premises of DA and AC arguments fail to cite as reasons the factors on which the warrentedness of their conclusions properly depends. So even in cases where DA and $\mathrm{AC}$ do result in true premises that lead to a true conclusion, this is a matter of accident as far as the inference is concerned. Therefore, even though DA and AC do not always lead to error, it is bad advice to treat them as cogent or probative by default. Hence, we should not presumptively rely upon them, but should rather seek information that either justifies or counts against their conclusions.

Arguments that deny the antecedent or affirm the consequent thus rely upon recognizable patterns of incogent but deceptively compelling reasoning. Shall this be called "fallacious"? Well, "what's in a word?" one might ask. Call them what you will! Our claim is that DA and AC inferences, unless they are suitably qualified, make for bad arguments that are epistemically irresponsible, seemingly predictable, and likely preventable. The rational and discursive value of a literacy of the fallacies was that it promised to inculcate a set of cognitive habits by which we might recognize such errors of reasoning in our own and others' thought and discourse, and deploy the appropriate, learned error-avoidance procedures. Thus, in as much as we find it accurate to classify DA and AC as fallacious, we further recommend that it is rationally prudent to treat them as such.

Acknowledgements: We consider this joint work; our names are listed in alphabetical order.

Excerpts from previous versions of this paper were presented at: (i) the higher seminar in theoretical philosophy, Lund University, Sweden, 11 March 2014; (ii) the $15^{\text {th }}$ biennial conference on Argumentation, Wake Forest University, WinstonSalem, North Carolina, USA, 11-13 April 2014; (iii) the 2nd International conference on Rhetoric, Days of Ivo Skaric (DIS 2014), April 23-26, Brac, Croatia; (iv) Giornate Tridentine di Retorica 14 (GTR 2014), Trento, Italy, June 12-13; and (v) the conference of the International Society for the Study of Argumentation, Amsterdam, The Netherlands, 1-5 July 2014. 
Other than from audience feedback at these events, our paper has benefitted from exchanges with several others who deserve our recognition and thanks. First among these is John Woods whose perspicacious commentary on a previous version helped clarify several important claims, avoid even more embarrassing errors, as well as provided us with the "Cold Beer" example. Next are George Masterton and Stefan Schubert, who early on picked out some serious mistakes. We moreover thank Lilian Bermejo Luque, Ian Dove, Ulrike Hahn, Fabio Paglieri, Federico Puppo, Andrei Moldovan, and Doug Walton who read and commented on (parts of) various drafts and provided additional references. Finally, we are indebted to the anonymous referees who reviewed the paper.

Frank Zenker acknowledges funding of salaries from the Swedish Research Council and the Ragna Söderberg Foundation, as well as for travel funding from the Hultengrens Fund for Philosophy, the Elisabeth Rausings Memorial Fund, and the Uno Otterstedts Fund.

\section{References}

Adams, E. (1965). A logic of conditionals. Inquiry, 8, 166-197.

Adams, E. (1975). The logic of conditionals: An application of probability to deductive logic. Dordrecht: Reidel.

Adler, J. (1994). Fallacies and alternative interpretations. Australasian Journal of Philosophy, 72, 271-282.

Auwera, J. van der (1997a). Pragmatics in the last quarter century: The case of conditional perfection. Journal of Pragmatics, 27, 261-274.

Auwera, J. van der (1997b). Conditional perfection. In: A. Athanasiadou \& R. Dirven (Eds.), On conditionals again (pp. 169-190). Amsterdam: John Benjamins Publishing Company.

Barbey, A.K., \& Sloman, S.A. (2007). Base-rate respect: from ecological rationality to dual processes. Behavioral and Brain Sciences, 30, 241-297.

Bennett, J. (2003). A philosophical guide to conditionals. Oxford: Clarendon Press.

Blamey, J. (2013). Upping the stakes and the preface paradox. In: F. Zenker (Ed.), Bayesian argumentation (pp. 195-210). Dordrecht: Springer.

Burke, M. (1994). Denying the antecedent: A common fallacy? Informal Logic, 16, 23-30. 
Croskerry, P. (2003). The importance of cognitive errors in diagnosis and strategies to minimize them. Academic Medicine, 78, 775-780.

Croskerry, P., Singhal, G., \& Mamede, S. (2013a). Cognitive debiasing 1: origins of bias and theory of debiasing. British Medical Journal, Quality and Safety, 22, Suppl. 2, ii58-ii64.

Croskerry, P., Singhal, G., \& Mamede, S. (2013b). Cognitive debiasing 2: impediments to and strategies for change. British Medical Journal, Quality and Safety, 22, Suppl. 2, ii65-ii72.

Eddy, D.M. (1982). Probabilistic reasoning in clinical medicine: problems and opportunities. In D. Kahneman, P. Slovic \& A. Tversky (Eds.) Judgment under uncertainty: Heuristics and biases (pp. 249-267). New York: Cambridge UP.

Edgington, D. (2005). On conditionals. Mind, 104, 235-329.

Edgington, D. (2009). Conditionals. In E. Zalta et. al. (eds.), Stanford Encyclopedia of Philosophy. http://plato.stanford.edu/archives/spr2009/entries/conditionals/

Eemeren, F.H. van, \& Grootendorst, R. (2004). A systematic theory of argumentation: The pragma-dialectical approach. Cambridge: Cambridge UP.

Ellis, M. (1991). Linguistic and semantic factors in conditional reasoning. PhD dissertation, Plymouth: Polytechnic South West.

Elstein, A. (1999). Heuristics and biases: selected errors in clinical reasoning. Academic Medicine, 74, 791-794.

Evans, J. St. B.T. (1998). Matching bias in conditional reasoning: Do we understand it after 25 years? Thinking and Reasoning, 4, 45-82.

Evans, J.St. B.T. \& Lynch, J.S. (1973). Matching bias in the selection task. British Journal of Psychology, 64, 391-397.

Evans, J. St. B.T., Newstead, S.E., \& Byrne, R.M.J. (1993). Human reasoning: The psychology of deduction. Hillsdale, NJ: Erlbaum.

Evans, J. St. B.T., \& Over, D.E. (2004). If. New York: Oxford UP.

Fearnside, W., \& Holther, W. (1959). Fallacy: The counterfeit of argument. Englewood Cliffs, NJ: Prentice-Hall.

Floridi, L. (2009). Logical fallacies as informational shortcuts. Synthese, 167, 317-325.

Fogelin, R. (1985). The logic of deep disagreements. Informal Logic, 7, 1-8. [Reprinted in Informal Logic, 25, 3-11 (2005).]

Gabbay, D. \& Woods, J. (2005). The reach of abduction: Insight and trial, volume 2 of $A$ practical logic for cognitive systems. Amsterdam: North Holland. 
Geis, M., \& Zwicky, A. (1971). On invited inferences. Linguistic Inquiry, 2, 561-566.

Gigerenzer, G., \& Hoffrage, U. (1995). How to improve Bayesian reasoning without instruction: frequency formats. Psychological Review, 102, 684-704

Girotto, V., Mazzocco, A, \& Tasso A. (1997). The effect of premise order in conditional reasoning: a test of the mental model theory. Cognition, 63, 1-28.

Godden, D. (2005). Deductivism as an interpretative strategy: A reply to Groarke's defense of reconstructive deductivism. Argumentation and Advocacy, 41, 168-183.

Godden, D., \& Walton, D. (2004). Denying the antecedent as a legitimate argumentative strategy: A dialectical model. Informal Logic, 24, 219-243.

Gordon, T., Prakken, H., \& Walton, D. (2007). The Carneades model of argument and burden of proof. Artificial Intelligence, 171, 875-896.

Graber M. (2005). Diagnostic error in internal medicine. Archives of Internal Medicine, 165, 1493-1499.

Grice, P. (1989). Studies in the way of words. Cambridge, MA: Harvard UP.

Harris, A. J. L., Hsu, A. S., \& Madsen, J. K. (2012). Because Hitler did it! Quantitative tests of Bayesian argumentation using ad hominem. Thinking \& Reasoning, 18, 311-343.

Hahn, U., \& Oaksford, M. (2007). The rationality of informal argumentation: A Bayesian approach to reasoning fallacies. Psychological Review, 114, 704-732.

Hahn, U., \& Oaksford, M. (2012). Rational argument. In K. Holyoak \& R. Morrison (Eds.), The Oxford handbook of thinking and reasoning (pp. 277-298). Oxford: Oxford UP.

Hamblin, C. (1970). Fallacies. London: Methuen.

Hansen, H. \& Pinto, R. (Eds.). (1995). Fallacies: Classical and contemporary readings. University Park, PA: Pennsylvania State UP.

Harper, W. (1981). A sketch of some recent developments in the theory of conditionals. In: W. Harper, R. Stalnaker, \& C. Pearce (Eds.), Ifs: Conditionals, belief, decision, chance, and time, (pp. 3-38). Dordrecht: Reidel.

Hitchcock, D. (1995). Did Jesus commit a fallacy? Informal Logic, 17, 297-302

Hitchcock, D. (1998). Does the traditional treatment of enthymemes rest on a mistake? Argumentation, 12, 15-37.

Horn, L. (2000). From if to iff: Conditional perfection as pragmatic strengthening. Journal of Pragmatics, 32, 289-326. 
Howson, C., \& Urbach, P. (1993). Scientific reasoning: The Bayesian approach, $2^{\text {nd }}$ ed. La Salle, IL: Open Court.

Jackson, F. (1987). Conditionals. Oxford: Blackwell.

Jackson, F. (Ed.). (1991). Conditionals. New York: Oxford UP.

Jeffrey, R. (2004). Subjective probability: The real thing. Cambridge: Cambridge UP.

Kahneman, D., \& Tversky, A. (1979). Prospect theory: An analysis of decision under risk. Econometrica, 47, 263-291.

Kenyon, T. (2914). False polarization: debiasing as applied social epistemology. Synthese, 191, 2529-2547.

Kneale, W., \& Kneale, M. (1962). The development of logic. Oxford: Clarendon Press.

Korb, K. (2003). Bayesian informal logic and fallacy. Informal Logic, 23, 41-70.

Lewiński, M. (2011). The paradox of charity. Informal Logic, 32, 403-439.

Mendela, R., Traut-Mattauscha, E., Jonasa, E., Leuchta, S, Kanea, J., Mainoa, K., Kisslinga, W., \& Hamanna, J. (2011). Confirmation bias: why psychiatrists stick to wrong preliminary diagnoses. Psychological Medicine, 41, 2651-2659.

Moldovan, A. (2009). Pragmatic considerations in the interpretation of denying the antecedent. Informal Logic, 29, 309326.

Nickerson, R. (1998). Confirmation bias: A ubiquitous phenomenon in many guises. Review of General Psychology, 2,175220.

Norman G., Eva K. (2010). Diagnostic error and clinical reasoning. Medical Education, 44, 94-100.

Oaksford, M. \& Chater, N. (2008). Probability logic and the modus ponens - modus tollens asymmetry in conditional inference. In: N. Chater, \& M. Oaksford (Eds.), The probabilistic mind: prospects for Bayesian cognitive science (pp. 97120). Oxford: Oxford UP.

Oaksford, M., \& Chater, N. (2009). Précis of Bayesian rationality: The probabilistic approach to human reasoning. Behavioural and Brain Sciences, 32, 69-120.

Oaksford, M., Chater, N., \& Larkin, J. (2000). Probabilities and polarity biases in conditional inference. Journal of Experimental Psychology: Learning, Memory and Cognition, 26, 883-889.

Paglieri F., \& Woods J. (2011a). Enthymematic parsimony. Synthese, 178, 461-501.

Paglieri F., \& Woods J. (2011b). Enthymemes: From reconstruction to understanding. Argumentation, 25, 127-139. 
Denying Antecedents and Affirming Consequents 133

Peirce, C.S. (1998). The essential Peirce: Selected philosophical writings 1893-1913, vol. 2. Peirce Edition Project, N. Houser et. al. (Eds.). Bloomington, IN: Indiana University Press.

Perkins, D. N. (2002). Standard logic as a model of reasoning: The empirical critique. In: R. H. Johnson, H. J. Ohlbach, D. M. Gabbay, \& J. Woods (Eds.). Handbook of the logic of argument and inference: The turn towards the practical (pp. 187-223). Amsterdam: Elsevier.

Pelletier, F., \& Elio, R. (2005). The case for psychologism in default and inheritance reasoning, Synthese, 146, 7-35.

Pines J. (2006). Profiles in patient safety: confirmation bias in emergency medicine. Academic Emergency Medicine, 13, 90-94.

Quine, W. (1982). Methods of logic, $4^{\text {th }}$ ed. Cambridge, MA: Harvard UP.

Ramsey, F. (1990). General propositions and causality [1929]. In H. Mellor (Ed.), F.P. Ramsey: Philosophical Papers (pp. 145-165). Cambridge: Cambridge UP.

Rapp, C. (2010). Aristotle's Rhetoric. In Zalta, E.N. (Ed.). The Stanford Encyclopedia of Philosophy (Spring 2010 Edition)

http://plato.stanford.edu/archives/spr2010/entries/aristotlerhetoric/ (accessed 12 Feb 2015).

Salmon, W. (1984). Logic, $3^{\text {rd }}$ ed. Englewood Cliffs, NJ: Prentice-Hall.

Sanford, D. (2003). If $P$, then $Q$ : Conditionals and the foundation of reasoning, $2^{\text {nd }}$ ed. New York: Routledge.

Scriven, M. (1959). Truisms as grounds for historical explanations. In P. Gardiner (Ed.), Theories of history (pp. 443-475). New York: The Free Press.

Simon, H.A. (1956). Rational choice and the structure of the environment. Psychological Review, 63, 129-138.

Sober, E. (2002). Intelligent design and probability reasoning. International Journal for Philosophy of Religion, 52, 65-80.

Stalnaker, R. (1968). A theory of conditionals. Studies in logical theory, American Philosophical Quarterly monograph, no. 2 (pp. 98-112). Oxford: Blackwell.

Stein, E. (1996). Without good reason: The rationality debate in philosophy and cognitive science. Oxford: Oxford University Press.

Stone, M. (2012). Denying the antecedent: Its effective use in argumentation. Informal Logic, 32, 327-356.

Strawson, P. (1952). Introduction to logical theory. London: Methuen.

Wagner, C.G. (2004). Modus tollens probabilized. British Journal for Philosophy of Science, 55, 747-753.

(C) David Godden and Frank Zenker. Informal Logic, Vol. 35, No. 1 (2015), pp. 88-134. 
134 David Godden and Frank Zenker

Walton, D. (1995). A pragmatic theory of fallacy. Tuscaloosa, AL: University of Alabama Press.

Walton, D. (2002). Are some modus ponens arguments deductively invalid? Informal Logic, 22, 19-46.

Walton, D. (2004). Abductive reasoning. Tuscaloosa, AB: University of Alabama Press.

Wason (1966). Reasoning. In B.M. Foss (Ed.), New horizons in psychology I (pp. 106-137). Harmandsworth: Penguin.

Willingham, D.T. (2007). Critical thinking: Why is it so hard to teach? American Educator, 31, 8-19.

Woods, J. (2013). Errors of reasoning: Naturalizing the logic of inference. London: College Publications.

Woods, J. \& Walton, D. (2007). Fallacies: Selected papers 1972-1982. London: College Publications.

Zenker, F. (2015). Denying the Antecedent Probabilized: a Dialectical View. In: Eemeren, F.H. van, Garssen, B., Godden, D, and Mitchell, G. (eds). Proceedings of the 8th International Conference of the International Society for the Study of Argumentation (ISSA), July 2014 (pp. xx-yy). Amsterdam: SicSat (forthcoming). 